\title{
Impact of the internal variability on the cyclone tracks simulated by a regional climate model over the Med-CORDEX domain
}

\author{
Emilia Sanchez-Gomez ${ }^{1} \cdot$ Samuel Somot $^{2}$
}

Received: 27 December 2015 / Accepted: 8 October 2016 / Published online: 21 October 2016

(C) The Author(s) 2016. This article is published with open access at Springerlink.com

\begin{abstract}
Regional climate models (RCMs) constitute a powerful tool to study and understand climate variability and change at local scales. Nevertheless, to correctly interpret regional climate simulations, a number of uncertainties need to be considered. In this study, we investigate the so-called Internal Variability (IV) of an RCM. The IV can be defined as the degree of irreproducibility in an RCM solution observed when it is conducted by the same lateral boundary conditions (LBCs) but initialised from different initial states. The main goal of this work is to investigate how the IV affects the cyclone tracks simulated by an RCM over a Mediterranean domain. For standard variables such as sea level pressure, $2 \mathrm{~m}$ temperature and precipitation, our results over the Mediterranean region are consistent with studies conducted over other geographical domains: the $\mathrm{IV}$ is stronger at the easternmost part of the domain, where the control exerted by the LBCs is weaker; the IV shows a strong seasonal dependence, reaching larger values in summer than in winter. We show here that the IV values associated with the density of cyclone tracks are much stronger than for the other documented variables, reaching more
\end{abstract}

This paper is a contribution to the special issue on MedCORDEX, an international coordinated initiative dedicated to the multi-component regional climate modelling (atmosphere, ocean, land surface, river) of the Mediterranean under the umbrella of HyMeX, CORDEX, and Med-CLIVAR and coordinated by Samuel Somot, Paolo Ruti, Erika Coppola, Gianmaria Sannino, Bodo Ahrens, and Gabriel Jordà.

Emilia Sanchez-Gomez

sanchez@cerfacs.fr

1 CERFACS/CNRS-CECI, 42 Av. G. Coriolis, 31057 Toulouse Cedex, France

2 Meteo-France/CNRS, CNRM, 42, Av. G. Coriolis, Toulouse, France than $50 \%$ of the estimated total variability. Concerning the cyclone characteristics, long travelling tracks are associated to a greatest IV. Within the latter cyclone category, the fast moving cyclones seems to exhibit also larger IV values. A secondary IV maximum is observed for static cyclones with short travelling distances (thermal lows) during the warm season.

Keywords Regional climate modelling · Uncertainties · Internal variability $\cdot$ Mediterranean cyclones

\section{Introduction}

Regional Climate Models (RCMs) constitute an attractive approach to provide high-resolution climate simulations at an affordable computational cost. RCMs are powerful tools to simulate and understand climate phenomena at fine scales, which cannot be resolved by a General Circulation Model (GCMs). Recently, several coordinated efforts in an international context have emerged to improve the regional climate modelling and understanding, as well as to provide regional climate information to users. In particular, the World Climate Research Program (WCRP) has launched the Coordinated Regional Climate Downscaling Experiment (CORDEX) programme, aimed at producing an ensemble of dynamical and statistical downscaling simulations, considering multiple large-scale forcings and several spatial domains over the world (Giorgi et al. 2009; Nikulin et al. 2012; Jacob et al. 2013; Ruti et al. 2015).

When analysing climate variability and change on a modelling-based approach (either regional or global), several sources of uncertainty should be considered. These uncertainties arise from the model formulation (dynamics and choice of physical parameterizations), its forcings 
(surface and Lateral Boundary Conditions (LBCs), Greenhouse Gases (GHGs) and aerosol concentrations); and also from the intrinsic chaotic behaviour of climate. Some studies have shown that RCMs forced by identical LBCs but initialized from different initial conditions can diverge towards different solutions. This degree of irreproducibility in the RCM solution is often called the internal variability (IV hereinafter) of an RCM. The IV has been intensively studied over the North America domain (Caya and Biner 2004; de Elia et al. 2007; Alexandru et al. 2007; LucasPicher et al. 2008a, b; Separovic et al. 2008 and Laprise et al. 2008); but also over the Arctic region (Rinke et al. 2004; Zahn et al. 2008; Cretat et al. 2011; Nikiema and Laprise 2011a, b), West Africa (Vanvyve et al. 2008), South Africa (Kgatuke et al. 2008), Eastern Asia (Giorgi and Bi 2000), Europe (Vannitsem and Chomé 2005) and Mediterranean region (Christensen et al. 2001). All these studies agree on the IV dependence on the strength of the lateral boundary forcing. A weak LBC control generally allows the RCM to have more degrees of freedom to generate its proper solution, and to diverge from the driving conditions. For example, when a large cyclonic anomaly is located inside the RCM domain, the large-scale atmospheric circulation is mainly parallel to the LBCs. Consequently, the RCM is less influenced by its LBCs and the IV becomes stronger. This large-scale atmospheric situation is often found over the Arctic, where the Polar vortex reduces the flow of new information in the RCM domain, leading to larger IV (Rinke and Dethloff 2000; Zahn et al. 2008).

Following this idea, the LBCs strength, and hence the IV, depend on various factors: the geographical location of the domain (IV can be larger over the tropical regions where the lateral boundary forcing is weaker, Kgatuke et al. 2008; Vanvyve et al. 2008); the size of the domain (IV increases with the domain size, Vannitsem and Chomé 2005); and the distance from the western boundaries at mid-latitudes (Lucas-Picher et al. 2008a, b). Concerning the seasonality, the IV presents larger amplitudes in summer in the Northern Hemisphere, due to stronger local processes (such as convection), combined with weaker LBC control (Caya and Biner 2004; Alexandru et al. 2007; Lucas-Picher et al. 2008a, b). The variable the most affected by IV in RCMs is the precipitation, rather than temperature or large-scale variables such as sea level pressure, since precipitation is associated with convective scale processes (Crétat et al. 2011). All the mentioned studies reveal that, in regional modelling, it is highly advisable to adopt a probabilistic approach (ensemble) to take into account IV effects, in particular when the focus is weather processes or case-study analysis.

In this context, very few studies have addressed the IV problem over the Mediterranean region and, to our knowledge, none of them on the widely-used Med-CORDEX domain (Ruti et al. 2015). The first study on the IV over the
Mediterranean region was carried out by Christensen et al. 2001. They computed the IV from a 6-member ensemble for the year 1982 as an uncertainty estimate, to address the statistical significance of the model differences with respect to observations. Herrmann et al. (2011) evaluated the ability of an RCM to simulate the temporal chronology of the daily surface winds over the Mediterranean Sea. They showed that the temporal correlation between the RCM winds and the observations decreases eastwards, away from the forcing exerted by the North Atlantic atmospheric flow. Even if their study is only based on one simulation, the documented behaviour is likely indicative of the presence of IV.

Motivated by these arguments, the aim of this work is to explore in more details the IV over the Mediterranean region. Besides the variables the most frequently investigated in IV studies (temperature, precipitation, surface pressure), the novelty of this work is the analysis of the IV effects on the Mediterranean cyclones. Indeed, the Mediterranean region is characterized by a high cyclone activity (Neu et al. 2012). Due to strong thermal contrast between the continental and oceanic areas, atmospheric instabilities frequently generate thermal lows (stationary cyclones), specially in summer (Gaertner et al. 1993; Maheras et al. 2001). These shallow lows are strongly linked to mesoscale convective processes and inside the RCM domain, they can likely be affected by the IV. On the other hand, the Mediterranean cyclones play an important role on the climate variability in the region (Trigo et al. 2000; Lionello et al. 2006; Gaertner et al. 2007; Walsh et al. 2014). They are also responsible for the occurrence of rainfall and wind extremes in the Mediterranean (Jansà et al. 2001; Nissen et al. 2010; Raveh-Rubin and Wernli 2015). Recently, Flaounas et al. (2013) investigated the added value of an RCM in simulating the Mediterranean cyclones.

To better illustrate the context of this work, Fig. 1 shows the tracks for the Medicane event that occurred between the 13th and 16th December 2005, determined from ERAInterim reanalysis (Dee et al. 2011) and some members of an ensemble of 10 members performed with the ALADIN regional climate model. As shown in Fig. 1, even if they are driven by the same LBCs, only 4 members out of 10 are able to capture a cyclone event at the same location and time as the real Medicane, and the cyclone tracks and characteristics (not shown) are very different from one member to another.

The main scientific questions addressed in this work are the following:

- How does the IV affect standard variables such as sea level pressure, $2 \mathrm{~m}$ temperature and precipitation in the Mediterranean region? Are these impacts consist- 
Fig. 1 Cyclone tracks for the Medicane event occurring between the 13th and 16th December of 2005. The cyclone track determined from ERAI reanalysis is represented in black, and those for the ALADIN members are represented by orange, pink, blue and cyan colors. Only 4 out of 10 members are able to capture the Medicane episode. The black star marker represents the initial point of the Medicane track

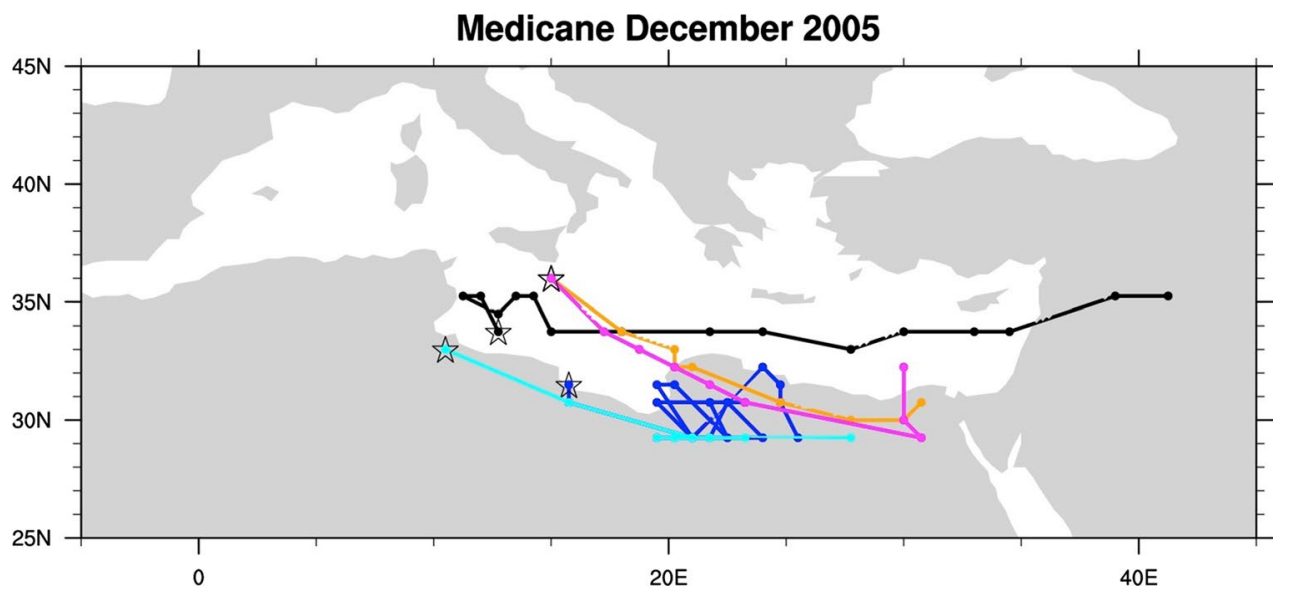

ent with the IV characteristics documented in previous studies over other geographical domains?

- How does the IV affect the different Mediterranean cyclones populations (thermal lows, fast moving cyclones)?

This paper is organized as follows: The ALADIN regional climate model is briefly described in Sect. 2, together with the experimental set-up adopted to conduct the simulations. A description of the tracking algorithm to identify Mediterranean cyclones is also provided. Section 3 presents a validation of ALADIN in simulating the Mediterranean cyclones. Section 4 is devoted to the general analysis of the IV, including Mediterranean cyclones. Finally, the summary and conclusions are presented in Sect. 5.

\section{Description of model, experiments and methodology}

\subsection{Description of the RCM ALADIN-climate}

In this study the regional climate model ALADIN version 5.2 (Aire Limitée Adaptation dynamique Développement InterNational) is used in an atmospheric forced configuration over the Med-CORDEX spatial domain (Ruti et al. 2015, www.medcordex.eu). For this configuration, ALADIN operates on a Lambert conformal projection for panMediterranean area at the horizontal resolution of $50 \mathrm{~km}$ centred at $14^{\circ} \mathrm{E}, 43^{\circ} \mathrm{N}$ with 128 grid points in longitude and 90 grid points in latitude, including the relaxation and biperiodization (explained below) zones. This model version runs with 31 vertical levels.

ALADIN v5.2 shares both the dynamical core and the physical package with the version 5 of the atmosphere general circulation model ARPEGE-Climate (Déqué 2010). ALADIN and ARPEGE are bi-spectral models with a semiimplicit semi-Lagrangian advection scheme. Horizontal diffusion, semi-implicit corrections and horizontal derivatives are then computed with a finite family of analytical functions. Contrarily to the global ARPEGE model, the ALADIN grid is not periodic, so a bi-periodization is achieved on the grid-point space by adding a so-called extension zone, used only for Fourier transforms. On the other hand, the non-linear contributions to the equations are performed in the grid point space. In this current configuration, ALADIN includes an 11-point wide bi-periodization zone in addition to the more classical 8 points relaxation zone using the Davies technique (Davies 1976). Details on the physical parameterizations of ALADIN version 5.2 can be found in Radu et al. (2008), Colin et al. (2010) and Herrmann et al. (2011).

The RCM ALADIN has been previously evaluated and used in many applications, some details on its performance can be found in the literature using the Big-Brother framework (Radu et al. 2008; Colin et al. 2010), for the representation of the wind over the Mediterranean Sea (Herrmann et al. 2011), for the Mediterranean Sea water and heat budgets (Sanchez-Gomez et al. 2011), hydrological applications (Tramblay et al. 2013; Lucas-Picher et al. 2013) and for extreme precipitation (Déqué and Somot 2008; Colin et al. 2010). The current version of ALADIN has been also used in the framework of the regional CORDEX programme over 4 domains (Europe, Mediterranean, Africa, North America).

\subsection{Description of the numerical experiments}

The simulations used in this analysis consist of an ensemble of 10 members for the period 1979-2012 at $50 \mathrm{~km}$ horizontal resolution. In our approach, only the initial conditions, and not the lateral boundary forcings, are perturbed to generate the different members. Both the atmosphere and land 3D initial conditions are selected among the 1st of January of different years within the 1979-2012 period. These selected restart files are then simply renamed as the 
1st of January 1979 to start the 34-year long simulations. Previous experiments have shown that this straightforward initialization technique is adequate to ensure an optimal spread. No spin-up period has been considered for these simulations since, for the variables investigated here, the equilibrium state is reached a few days after the initialisation. It is noteworthy to recall that all the members have been generated by identical experimental set-up: In this configuration, ALADIN is driven by the ERAI reanalysis (80 $\mathrm{km}$ horizontal resolution at its full resolution), which is updated every $6 \mathrm{~h}$ during the simulation. Land surface conditions are set to an observed seasonal cycle. The sea surface temperature (SSTs) and the sea ice limit around the Black Sea are interannual forcings issued from ERAI. GHGs concentrations follow observed values for the period 1979-2012, whereas aerosol concentrations are fixed to the Tegen seasonal climatology (Tegen et al. 1997).

To our knowledge, this 10-member and 34-year ensemble is the largest ever provided to study the IV of an RCM. It represents a total of 340 years of ALADIN simulation.

\subsection{Statistics to estimate internal variability}

The IV generated by the ALADIN ensemble is estimated by using the same statistics introduced in Alexandru et al. (2007) and Lucas-Picher et al. (2008a). Basically, the IV is defined as the inter-member spread, computed from daily data for each grid point and for each day, as:

$I V(x, y, z, t)=\frac{1}{M} \sqrt{\sum_{i=1}^{M}\left(\operatorname{MEMBER}^{i}(x, y, z, t)-E M(x, y, z, t)\right)^{2}}$

where MEMBER denotes the member for a given variable, $M$ is the ensemble size (10 in the present case), and $\mathrm{EM}$ is the ensemble mean (computed by averaging over all the members). The coordinates $\mathrm{x}, \mathrm{y}, \mathrm{z}$ indicate the location for each grid point and the height level. In this work, only near surface fields are considered, hence the $\mathrm{z}$ dimension is not used. The " $\mathrm{t}$ " coordinate indicates the time axis; in the present case the time archive is expressed in days. From expression (1), the temporal mean of IV can be determined by averaging over all days (" $t$ " coordinate) within the time period. This allows the study of the spatial structure of IV. On the other hand, the spatial averages (over $\mathrm{x}$ and $\mathrm{y}$ coordinates) to obtain the IV time-series can be computed, in order to analyse the temporal evolution of IV.

As the atmospheric circulation variability presents a strong seasonality, we normalize IV by the estimation of the transient-eddy variability (TV hereinafter, Caya and Biner 2004; Lucas-Picher et al. 2008a). The TV can be considered as the internal variability of a GCM. The intermember spread generated by the same RCM driven by the same LBCs is expected to be smaller than TV (Alexandru et al. 2007; Lucas-Picher et al. 2008a; Laprise et al. 2008). In the present case, we assume that the members of the ensemble exhibit a similar temporal variance distribution; hence the TV can be estimated from the daily temporal variance of only one member. Finally, the relative internal variability (RIV) is computed as the ratio RIV $=$ IV/TV. In the following, the analysis will be presented in terms on RIV values for winter, defined as January-February-March (JFM), and summer defined by July-August-September (JAS).

\subsection{Tracking method to detect Mediterranean cyclones}

The tracking algorithm is based on the detection of maxima of relative vorticity at $850 \mathrm{hPa}\left(\zeta_{850}\right)$. The first step consists of identifying the cyclone centers, defined as local maxima of $\zeta_{850}$ within a radius of $380 \mathrm{~km}$, determined every $6 \mathrm{~h}$ from the numerical experiments. Previously, a smoothing of the $\zeta_{850}$ field is performed by a 9-grid points spatial filter, obtained by weighting by the inverse of the distance from the central point. In the second stage, trajectories are built by pairing the cyclone centers previously determined for consecutive time steps. Three criteria are used to connect the cyclone centers: (1) the first criteria takes into account the absolute vorticity field and its variation from the given cyclone center. If the variation between two cyclone centers is important (more than $40 \%$ ), the two centers are considered to belong to two different cyclones tracks. (2) The second criterion uses the wind components at 850 and $700 \mathrm{hPa}$, the latter representative from the middle troposphere, to determine two potential next positions of the cyclone track. The 850 and $700 \mathrm{hPa}$ positions are compared to the real position by the minimization of a distance criterion. (3) The third criterion ensures the trajectory coherence by minimizing the acceleration, in order to avoid the abrupt changes in the wind speed and direction of the movement. More insights of this method can be found in Ayrault and Joly (2000) and Flaounas et al. (2016).

Results from the inter-comparison of cyclones tracking methodologies presented in Flaounas et al. (2016), show that this tracking algorithm captures a large number of cyclone tracks compared to other tools, since it has an ability to detect weak cyclones. Besides, long lifetime cyclones are better identified with this method, whereas the frequency of extreme cyclone tracks is underestimated.

The detection algorithm is applied to ERAI reanalysis data and the 10 members of ALADIN, previously interpolated on the ERAI grid. It is worth to note that the relaxation zone is removed before the analysis, and that the tracking algorithm is applied on a domain smaller than the initial ALADIN domain, in order to discard those grid points near the edges and to eliminate any spurious effects at the borders. Once the cyclone tracks are identified, a pre-selection 
Fig. 2 DCT for Mediterranean cyclones for winter (JFM) and summer (JAS) averaged over the period 1979-2012. The first column represents ALADIN (units: tracks per season), the second column ERAI (units: tracks per season) and the third column the normalised difference (ALADIN-ERAI)/ERAI (units: \% of error). Vectors represent the mean cyclone tracks flow. The unit for the reference vector is $4 \mathrm{~ms}^{-1}$ for ERAI and ALADIN, and $1 \mathrm{~ms}^{-1}$ for the differences (which are not normalised in the case of vectors)
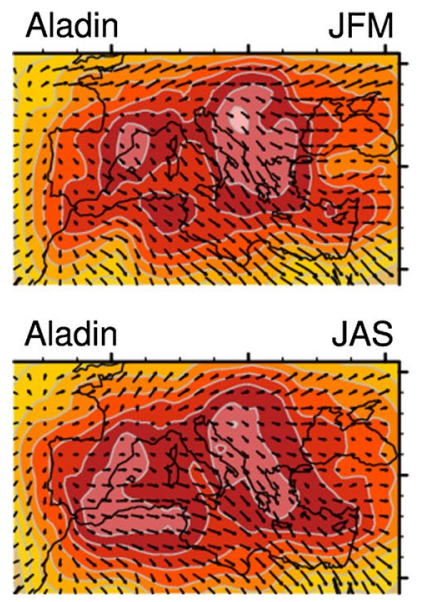

cyclones per season

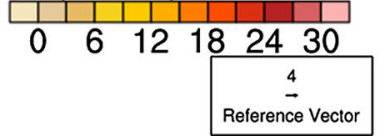

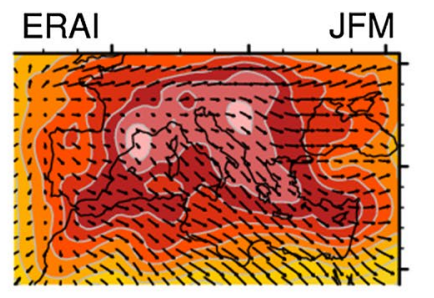
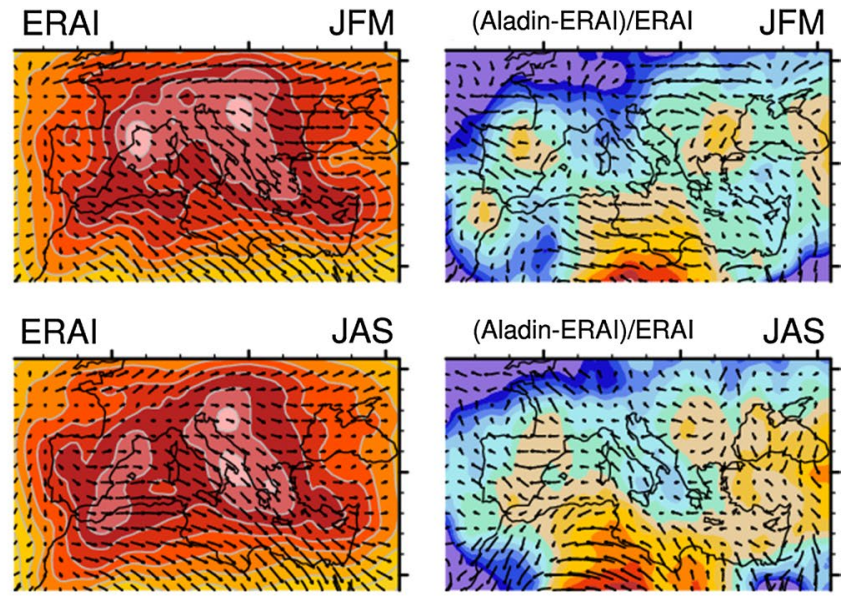

cyclones per season

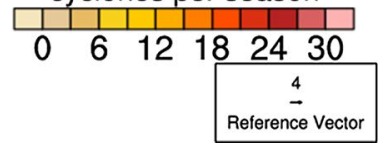

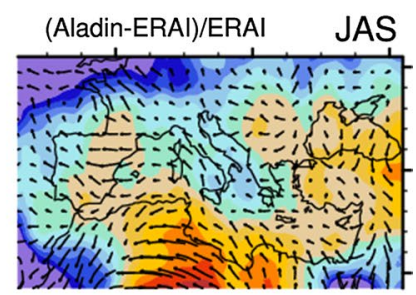

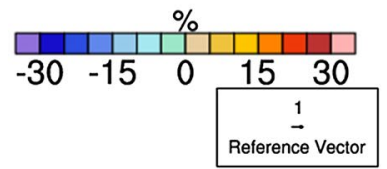

of cyclones is performed for the analysis. In our study only those systems lasting at least two days (9 points in the 6-h track) are retained. In the following, intense cyclones are defined here as those systems exceeding (at least once in their lifetime) the value of $\zeta_{850}=170 \times 10^{-6} \mathrm{~s}^{-1}$, that corresponds to the $90 \%$ percentile of the intensity statistical distribution.

\section{Simulation of Mediterranean cyclones by the RCM ALADIN}

The Mediterranean cyclones simulated by climate models have been already investigated in some studies as Trigo et al. (2002), Lionello et al. (2008), Flaounas et al. (2013, 2014). In their inter-comparison analysis, Flaounas et al. (2016, this issue) already shows that ALADIN is able to simulate correctly some properties (location, intensity) of the Mediterranean cyclones. In this section a more detailed evaluation of ALADIN is presented. We compare the model to the driving conditions ERAI. We are aware that the use of reanalysis data as reference dataset could lead to misleading interpretations. Indeed, horizontal resolution of the atmospheric reanalysis $(80-100 \mathrm{~km})$ is not adapted to a correct representation of cyclone systems. For this reason reanalysis can overestimate the low-pressure minimum at the cyclones center, and in the RCM the minimum pressure values could be lower than in the reanalysis. This could be an indication of an added value of the RCM, rather than a presence of a model biases. As higher resolution atmospheric reanalysis are unfortunately not available so far, ERAI becomes a good alternative, however the considerations discussed above should be taken into account when interpreting the results. Model errors are practically indistinguishable amongst the ALADIN members indicating that those biases are systematic; hence in the following model differences with respect to ERAI are shown for only one member of the ensemble.

\subsection{Spatial distribution of density of cyclone tracks}

Figure 2 shows the density of cyclone tracks (DCT hereinafter) for ALADIN, ERAI and the normalised ALADINERAI differences (expressed in \% of error) in JFM and JAS. For a given grid point, the DCT is first estimated by counting all the tracks located near this point in a radius of $300 \mathrm{~km}$. Then, this quantity is smoothed through a spatial Gaussian filter, by applying weights that decrease as the distance to the selected grid point increases. The mean cyclone flow is also presented by arrows, computed as an estimate of the mean direction of the cyclones displacement. In Flaounas et al. (2016), ALADIN exhibits a correct DCT spatial structure, with maxima located over the Gulf of Lyon, Ligurian Sea, north-western Africa, Adriatic and Ionian Seas and Balkans Peninsula (Trigo et al. 1999; Campins et al. 2011). Values over these regions can reach on average 20-30 cyclone tracks per season. The mean track flow indicates that generally, ALADIN and ERAI cyclones entering in the north of the domain are deviated towards northern Europe. However, most cyclones developing in the Mediterranean western coastal areas move towards the southeast.

The normalised differences ALADIN-ERAI/ERAI expressed in \%, show that in summer the DCT errors are larger in the eastern part. In summer as DCT is mostly associated to thermal lows occurrence, hence the presence 
Fig. 3 Density of cyclogenesis for Mediterranean cyclones for winter (JFM) and summer (JAS) averaged over the period 1979-2012. The first column represents ALADIN (units: tracks per season), the second column ERAI (units: tracks per season) and the third column the normalised difference (ALADIN-ERAI)/ERAI (units: \% of error). Vectors represent the mean cyclone tracks flow. The unit for the reference vector is $4 \mathrm{~ms}^{-1}$ for ERAI and ALADIN, and $1 \mathrm{~ms}^{-1}$ for the differences (which are not normalised in the case of vectors)
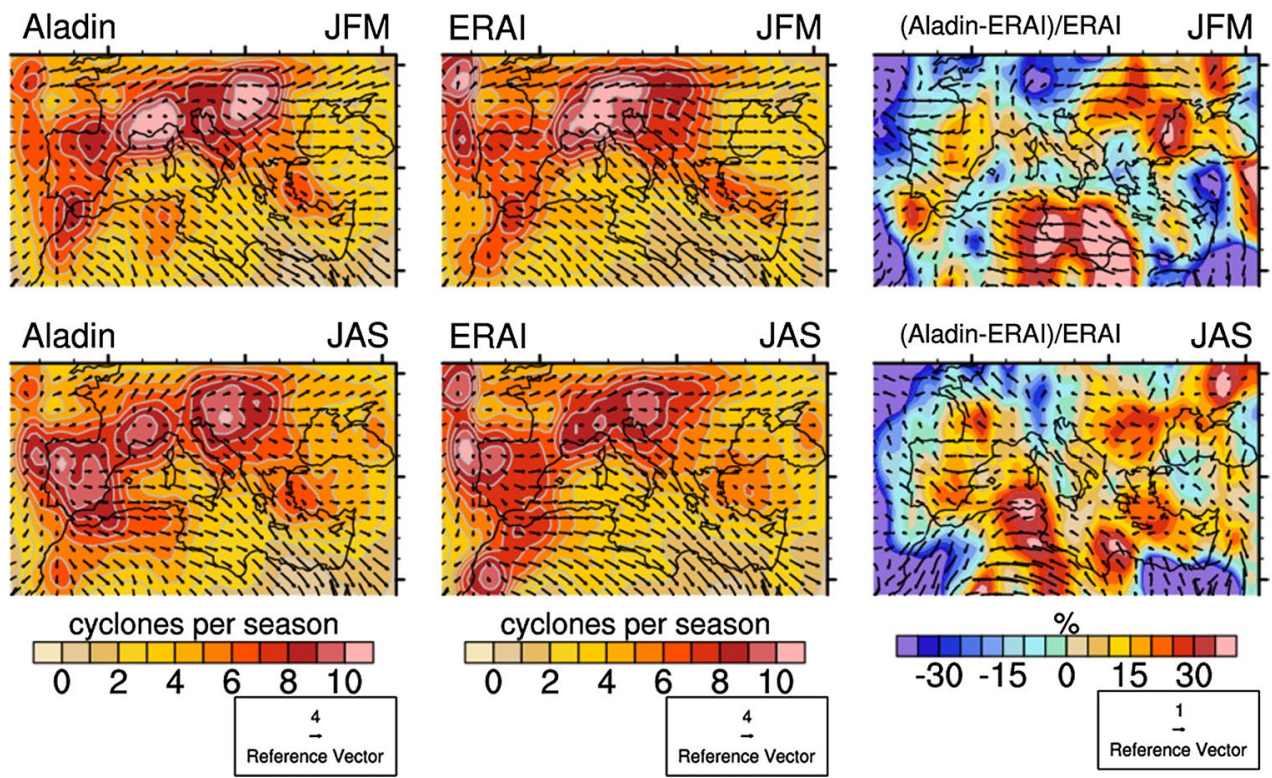

of stronger errors over the east may suggest that the RCM deviates more from ERAI forcing to produce its intrinsic thermal lows. For both seasons ALADIN underestimates the DCT (around $30 \%$ ) on the north-western boundary (Fig. 2), which may indicate that the RCM partly fails to capture the entrance of North Atlantic cyclones in the domain. This could be due to several causes: (1) the ratio between the 6-h coupling frequency between the driver and the RCM and the size or the relaxation zone ( 8 grid points and hence 400 at $50 \mathrm{~km}$ resolution). This means that, if the entering cyclone moves very fast, it would be able to "cross" the relaxation zone during the 6-h period without letting a strong footprint in between time $\mathrm{T}+00 \mathrm{~h}$ and $\mathrm{T}+06 \mathrm{~h}$. In consequence, this cyclone could be missed or more likely be weakened near the boundaries of the RCM domain. (2) Problems at the lateral boundaries of ALADIN connected to the model LBC set-up itself. (3) Even if the relaxation zone is not included in the analysis and the tracking domain is smaller than the original ALADIN domain, it is not excluded that the tracking algorithm could still induce some spurious effects on the lateral borders. All these problems need further investigation, but this is outside the scope of this study, mostly dedicated to the RIV.

Figure 2 shows also that ALADIN overestimated the DCT over northern Africa (around 10-20\% of error). Concerning the mean flow of cyclones, ALADIN presents an easterly bias compared to ERAI. This could suggest that in ALADIN cyclones are created but are not able to move eastwards at the same velocity as for ERAI.

The ability of ALADIN to create cyclones is evaluated by the density of cyclogenesis (Fig. 3). This density is determined by taking into account only the first time-step in each cyclone track. Figure 3 shows that the locations of the main cyclogenesis areas (Gulf of Lyon, Atlas Mountains, Ligurian Sea and Turkey coast) are well captured by ALADIN. However, the RCM shows a secondary maximum over the Balkans Peninsula in both seasons, which is not present in ERAI. Negative errors localized around the lateral boundaries, may indicate that some of the cyclones either are not able to enter the domain or are not created in the near-Atlantic zone. On the other hand, ALADIN overestimates cyclones generation in some areas as the Iberian Peninsula, northern Africa and the Balkans Peninsula.

It is interesting to evaluate those areas where cyclone tracks decay or exit from the RCM domain. An estimate of the cyclolysis has been obtained by computing the density of cyclolysis considering only the last time-step of each cyclone track (Fig. 4). In this case, the highest values of cyclolysis are located for both ALADIN and ERAI on the eastern and southeastern lateral boundaries. In general the spatial structure of the density of cyclolysis is correctly represented by ALADIN, nevertheless some biases appear in particular in JFM near the lateral boundaries (negative errors $\sim 30 \%$ ), and over the western part of the domain (positive errors 20-30\%). In JAS, an overestimation of cyclolysis occurs in the northeast of the Gulf of Lyon and east of the domain.

Finally, the DCT for intense cyclones is represented in Fig. 5. Focusing on ERAI, some areas exhibit values of DCT of 5-6 tracks/season in winter over the northernmost part of the domain. In summer the number of intense cyclones is lower and the maxima are located slightly southwards. The DCT for strong systems is clearly underestimated by ALADIN (more than $45 \%$ of error locally), particularly near the northern lateral boundaries. This is 
Fig. 4 Density of cyclolysis for Mediterranean cyclones for winter (JFM) and summer (JAS) averaged over the period 1979-2012. The first column represents ALADIN (units: tracks per season), the second column ERAI (units" tracks per season) and the third column the normalised difference (ALADIN-ERAI)/ERAI (units: \% of error). Vectors represent the mean cyclone tracks flow. The unit for the reference vector is $4 \mathrm{~ms}^{-1}$ for ERAI and ALADIN, and $1 \mathrm{~ms}^{-1}$ for the differences (which are not normalised in the case of vectors)
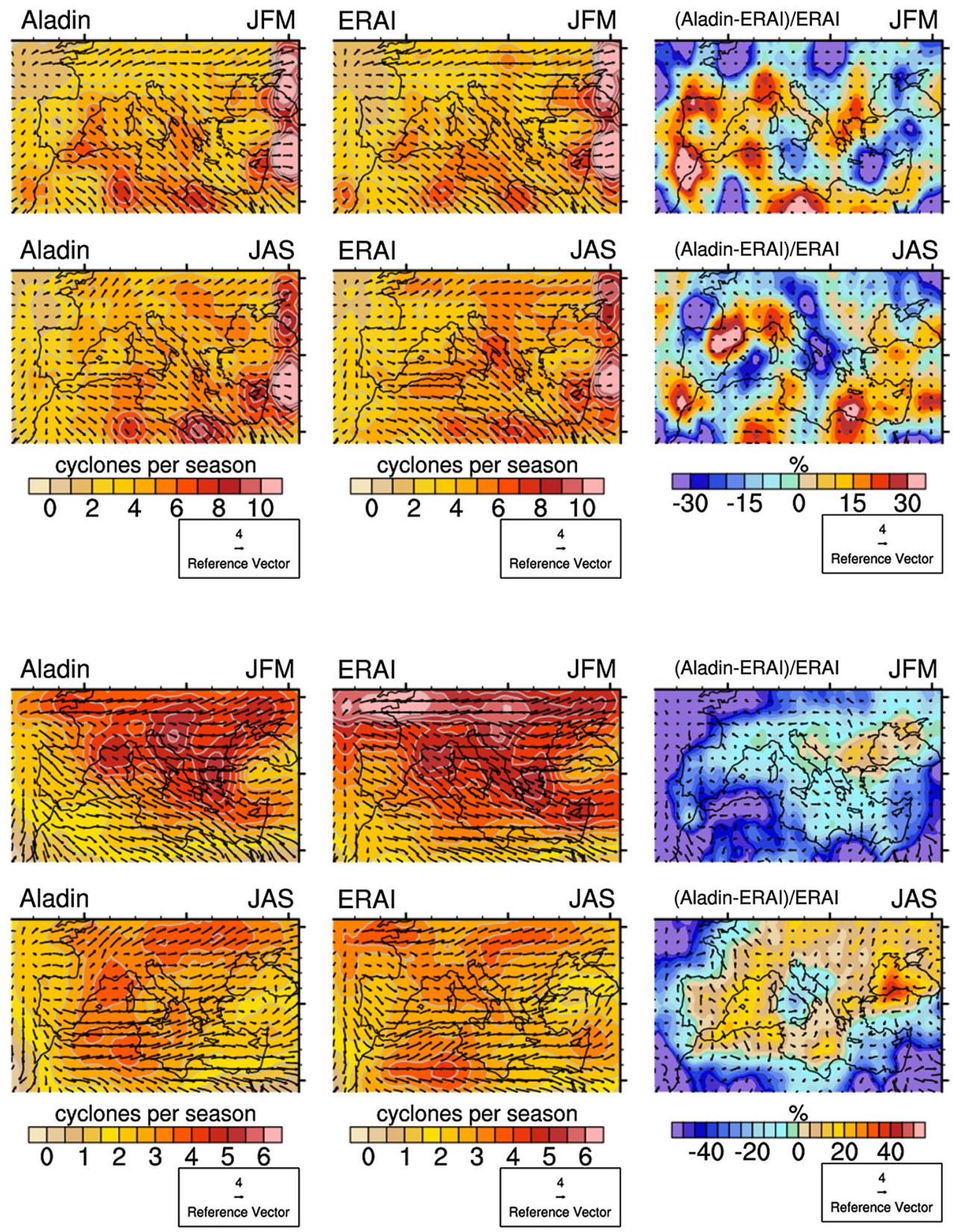

Fig. 5 DCT for intense cyclones for winter (JFM) and summer (JAS) averaged over the period 1979-2012. Intense cyclones are defined as cyclones exceeding the threshold value of $170 \times 10^{-6} \mathrm{~s}^{-1}$ during at least one time-step. The first column represents ALADIN (units: tracks per season), the second column ERAI (units: tracks per season) and the third column the normalised difference (ALADIN-ERAI)/ERAI (units: \% of error). Vectors represent the mean cyclone tracks flow. The unit for the reference vector is $4 \mathrm{~ms}^{-1}$ for ERAI and ALADIN, and $4 \mathrm{~ms}^{-1}$ for the differences (which are not normalised in the case of vectors)

also indicative of the problems previously discussed on Fig. 2. In summer, ALADIN exhibits a larger DCT values for intense cyclones in some areas, as the Levantine coast of Spain and the Black Sea.

\subsection{Statistical distributions for some cyclones properties}

To continue the ALADIN evaluation, some physical properties of cyclones have been analysed in terms of probability distribution functions (PDFs). The PDFs have been built by considering the whole Mediterranean domain and the full period of analysis (1979-2012). Figure 6
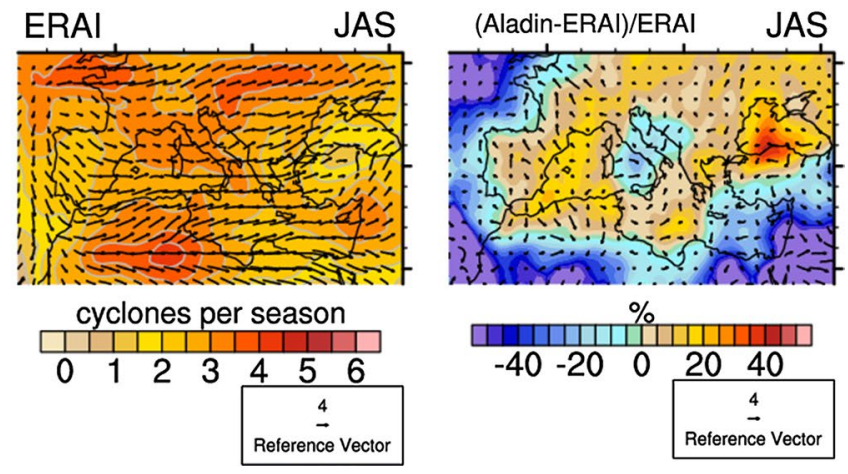

displays the respective PDFs for the ALADIN members and ERAI for the cyclones maximum intensity reached during the lifetime (these are the values of $\zeta_{850}$ ), the duration of cyclones lifetime (in days), the travelled distance and the mean velocity of the cyclone tracks, estimated by averaging all the velocities computed every $6 \mathrm{~h}$ time-step. Figure $6 \mathrm{a}, \mathrm{b}$ shows that in winter, the ALADIN ensemble provides a correct distribution of $\zeta_{850}$ compared to ERAI, though ALADIN underestimated the cyclones frequency around $\zeta_{850} \sim 50 \times 10^{-6} \mathrm{~s}^{-1}$. In summer, the ALADIN histogram is slightly shifted towards stronger vorticity values, indicating that the RCM overestimates the number of cyclones of medium intensities, in particular for values 
Fig. 6 Probability distribution function (PDFs) for several physical parameters of the Mediterranean cyclones in JFM (left) and JAS (right) for ERAI (black) and the 10 members of ALADIN (red): a, b intensity (maximum vorticity reached during the lifetime), $\mathbf{c}, \mathbf{d}$ track duration in days, $\mathbf{e}, \mathbf{f}$ distance travelled in $\mathrm{km}$ and $\mathbf{g}, \mathbf{h}$ track mean velocity in $\mathrm{m} / \mathrm{s}$
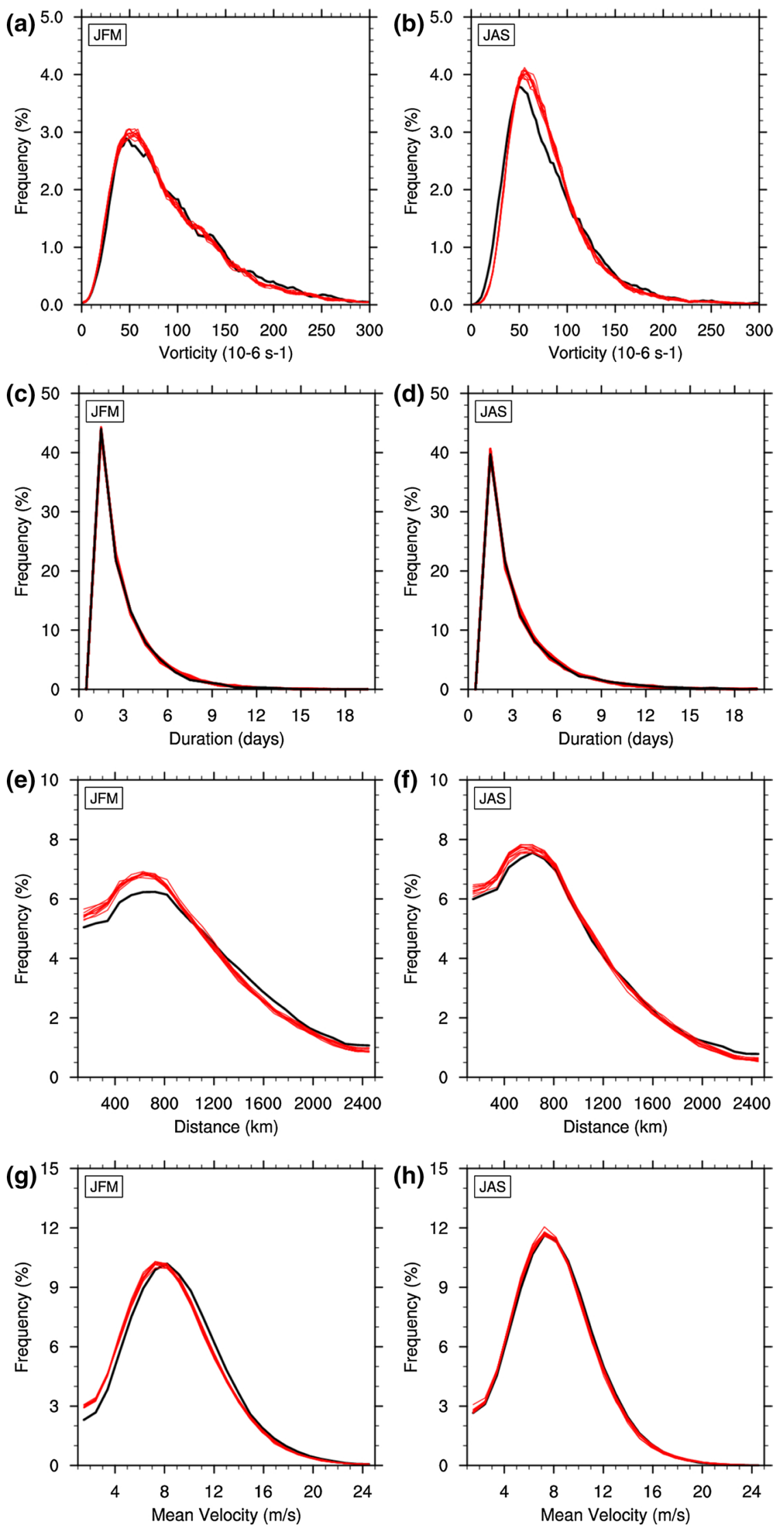
ranging between 50 and $100 \times 10^{-6} \mathrm{~s}^{-1}$. In both seasons the frequency of intense cyclones $\left(\zeta_{850}>170 \times 10^{-6} \mathrm{~s}^{-1}\right)$ is slightly lower in ALADIN than in ERAI. This can be mainly attributed to the underestimation of intense cyclones by ALADIN located around the boundaries of the domain, which may compensate with the overestimation observed inside the domain (Fig. 5), resulting in a weak PDF difference. Concerning the lifetime expectancy (Fig. 6c, d), the ALADIN and ERAI histograms are almost undistinguishable, confirming the ability of ALADIN to simulate this cyclone property.

ALADIN members show an overestimation of the number of cyclones for travelled distances ranging between 400 and $700 \mathrm{~km}$ (Fig. 6e, f), which constitute the stationary cyclones population (or thermal lows). However, the number of cyclones travelling longer distances (more than $1200 \mathrm{~km}$ ) is underestimated. To finish, the distribution of the mean velocity of cyclones is well simulated by ALADIN, however some biases are observed in winter (Fig. 6g, h): In particular, the histogram is slightly shifted towards decreasing values, suggesting that ALADIN simulated slower cyclones systems compared to ERAI (also seen in Figs. 4 and 5).

We have shown here that the RCM ALADIN and ERAI show high similarities in representing the main characteristics of the Mediterranean cyclones. Though it is used in many climate applications, ALADIN is actually an operational model for weather prediction in the Météo-France institution. It has been calibrated to correctly represent the extra-tropical cyclones, which can explain the good performance of ALADIN in representing the Mediterranean cyclones. However some differences from ERAI have been identified: ALADIN strongly underestimates the DCT near the western boundaries and it simulates more stationary cyclones (for travelled distances $<800 \mathrm{~km}$ ).

\section{Internal variability of ALADIN in the Med-CORDEX domain}

In this section the spatial and temporal behaviour of the internal variability of ALADIN is investigated. Following Sect. 2.3, the relative internal variability (RIV) is computed from daily data. The focus is first on standard variables as sea level pressure (PSL), $2 \mathrm{~m}$ air temperature (T2 m) and precipitation (PR). In a second stage, the RIV for the Mediterranean cyclones is analysed.

\subsection{Spatial distribution of the internal variability}

The RIV spatial structure in winter and summer (Fig. 7) reveals that for all the variables (PSL, T2 $\mathrm{m}$ and PR) the values are stronger over the eastern part of the domain.
We recall that the RIV is computed as the ratio between the IV (inter-members spread) and the TV (daily temporal variance of only one member). There is also a pronounced seasonal cycle; summer exhibits higher levels of RIV than winter. These results are consistent with a decrease of the strength of the boundary forcing eastwards, and with a weaker westerly flow in summer than in winter. The spatial structures in Fig. 7 show strong similarities to previous studies of RIV over the North America domain (Lucas-Picher et al. 2008a; Separovic et al. 2008), and South Africa domain (Crétat et al. 2011). However, the values of the internal variability obtained for the Mediterranean domain are lower than in other domains, probably because of a smaller domain size. In particular, largest values of RIV are found over the Balkans Peninsula, northeastern Europe and Turkey for all the variables, though the intensity of RIV is variable-dependent. Amongst the three variables, PSL (Fig. 7a, b) shows the weakest values of RIV, with maxima not exceeding $10 \%$ (in summer) of the total variability over the easternmost areas. As pointed out by Crétat et al. (2011), the chaotic variability is smaller for those variables connected to large-scale variability, as geopotential height or sea level pressure. T2 $\mathrm{m}$ (Fig. 7c, d) presents values of RIV that can reach $10-16 \%$ of the total variability over Turkey and around the Black Sea. The variable associated to strongest RIV is the PR (Fig. 7e, f), with maxima RIV values ranging from $\sim 15 \%$ in winter to more than $\sim 25 \%$ in summer. Note that for PR the RIV is larger over the ocean than over the continent in winter, whereas the opposite case is found in summer. In winter SSTs are warmer than the underlying atmosphere, enhancing the cyclogenesis over the sea. In summer, thermal heating over land likely contributes to the genesis of cyclones over the continent, in particular over the Atlas region and Turkey (Campins et al. 2011).

We focus now on the spatial structure of the RIV for the Mediterranean cyclone tracks. A daily DCT is computed from the detected cyclone tracks to obtain the RIV following Sect. 2.3. In the following, the IV and the TV are recomputed for each different population of cyclones (i.e. winter cyclones, summer cyclones, intense cyclones etc.). Figure 8 shows the values of RIV of the Mediterranean cyclones considering the same variables as for Figs. 2, 3, 4 and 5: DCT (Fig. 8a, b); density of cyclogenesis (Fig. 8c, d); density of cyclolysis (Fig. 8e, f); and DCT for intense cyclones (Fig. 8g, h). It is noteworthy to indicate that the spatial domain considered in Fig. 8 is not exactly the same as for Fig. 7 since as already mentioned in Sect. 2.4, the tracking method is applied on a rectangular grid, after the interpolation of the ALADIN members on the ERAI grid.

The spatial structure of the RIV for the DCT (Fig. 8a, b) shows strong resemblances to Fig. 7, though a considerably stronger RIV is found in cyclone tracks. Largest RIV 
Fig. 7 RIV values (\%) for a, b: PSL; $\mathbf{c}, \mathbf{d}$ : T2 $\mathrm{m}$ and $\mathbf{e}, \mathbf{f}$ precipitation in winter (left) and summer (right). The RIV is determined from the 10 members of ALADIN as explained in Sect. 2.3
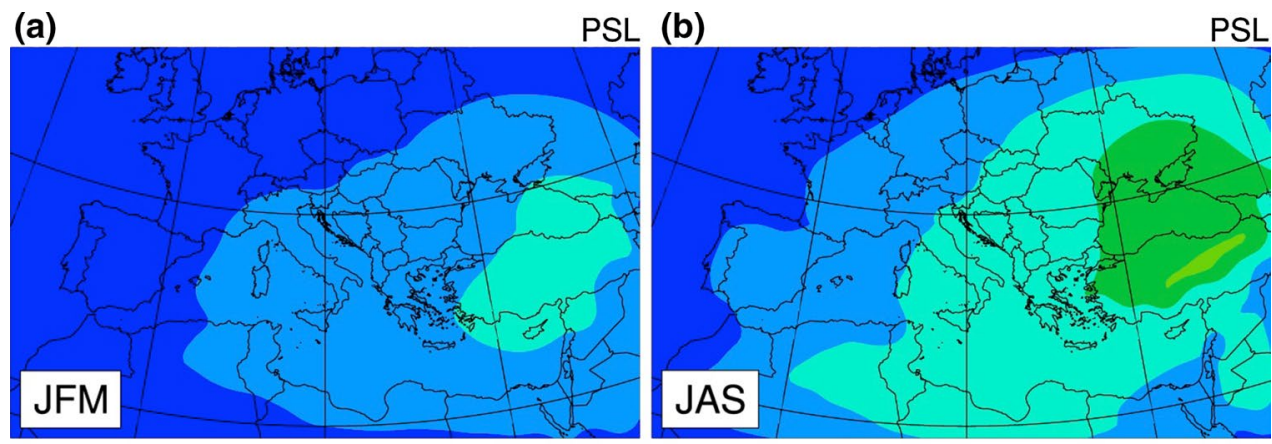

(c)

$\mathrm{T} 2 \mathrm{~m}$ (d)
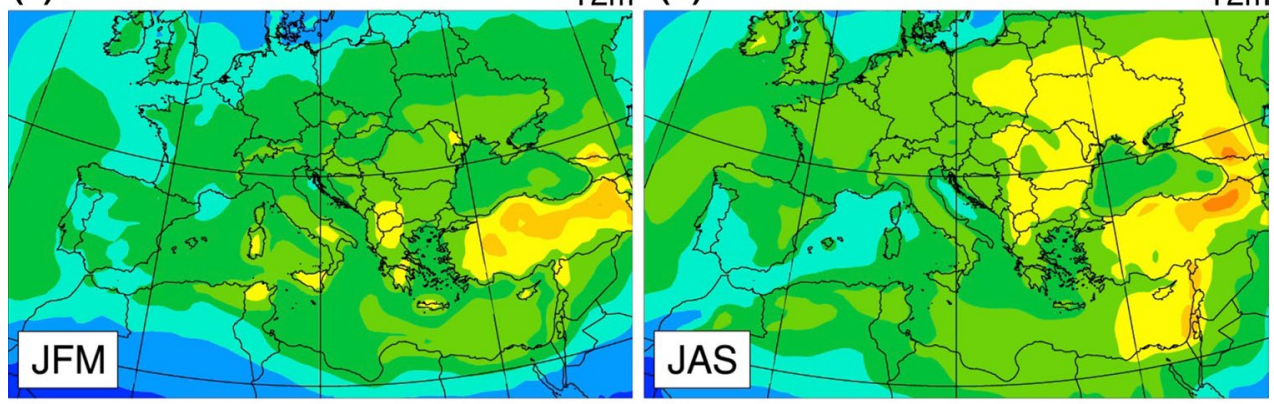

(e)

PR (f)

PR

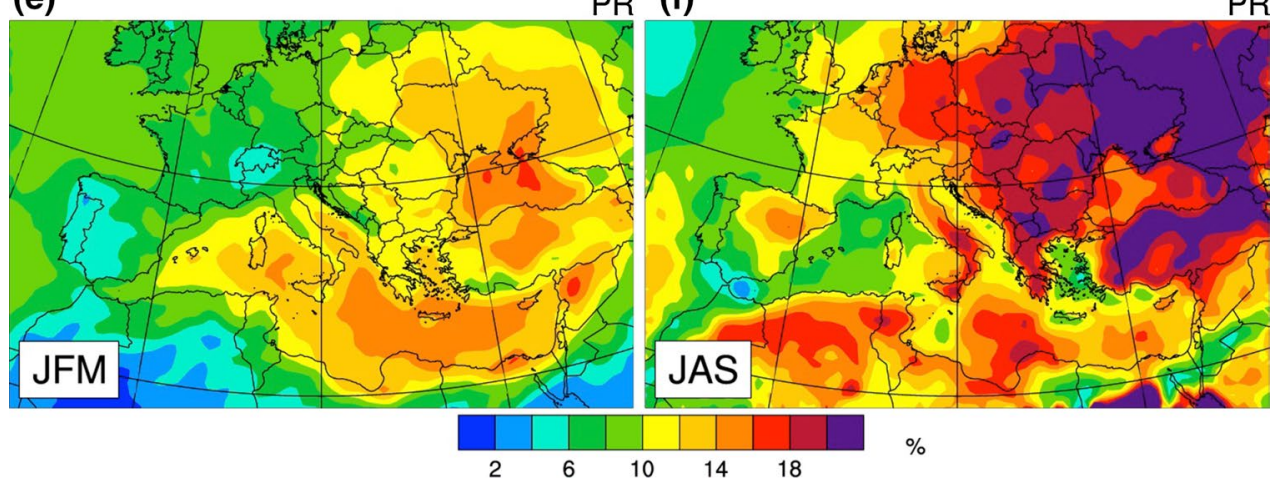

values $(\sim 50 \%$ in winter, more than $70 \%$ in summer) are located over the easternmost part of the Mediterranean domain. Even the western part of the domain, which is more controlled by the LBCs, presents values of RIV ranging between 30 and $40 \%$. Concerning the cyclogenesis (Fig. 8c, d), the areas the most affected by internal variability are essentially those that climatologically are related to a high cyclogenesis occurrence, as the Iberian Peninsula, the Gulf of Lyon, Adriatic Sea, Balkans Peninsula and Turkey (see Fig. 3). Nevertheless the RIV maxima are located in eastern part of the domain, with strongest values in summer. The large values of RIV located over the areas of thermal lows during the summer (Iberian Peninsula, northern Africa, eastern Mediterranean, Fig. 7b, d), could suggest that thermal lows are an important source of IV.

Figure 8e, f shows that strong RIV values $(\sim 50 \%)$ are found over the areas where the cyclones generally leave the domain at the east and southeast boundary (Fig. 4). Finally, RIV for intense cyclones (Fig. 8g, h) is lower, likely due to a larger large-scale forcing trough the LBCs. In this case, higher values of RIV are observed in winter (Fig. 8g). The most affected areas are the northern coasts of the Mediterranean Sea: Gulf of Lyon, Balkans Peninsula and Turkey, which exhibit RIV values of more than $30 \%$.

\subsection{Internal variability and cyclone characteristics}

At this point, the IV effects on different Mediterranean cyclone populations are investigated more in detail according to some cyclone characteristics. We focus on two cyclones properties: the travelled distance (D hereinafter) and the mean velocity ( $\mathrm{V}$ hereinafter) of the cyclone track. On this purpose, the PDFs from Fig. 6e-h are considered to classify the cyclone tracks into different groups according to the quantiles of each distribution. A previous analysis on the RIV of the DCT for each tercile population (not shown here) reveals that even if stationary cyclones provide a large source of IV, long-travelling cyclone tracks 


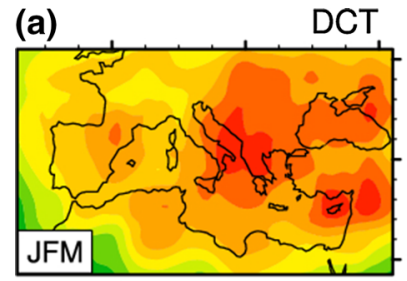

(c)

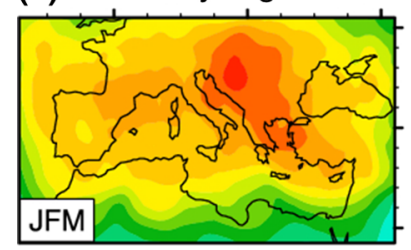

(e)

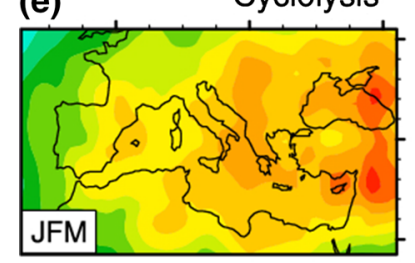

(g)

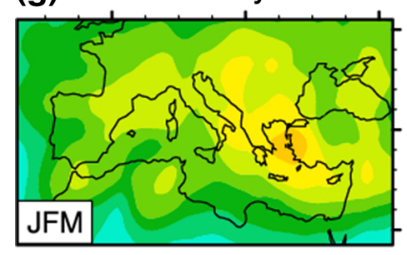

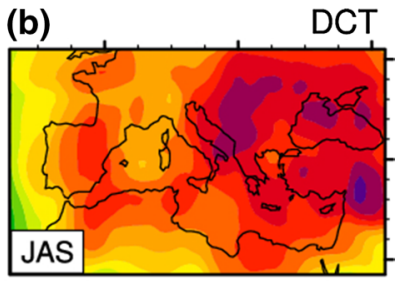

(d)

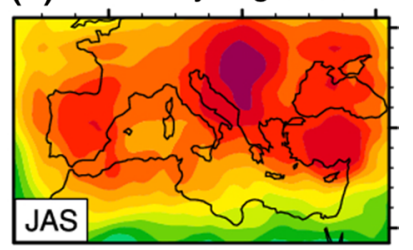

(f)

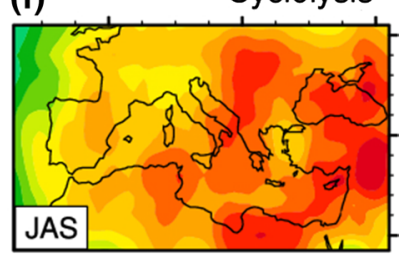

(h)

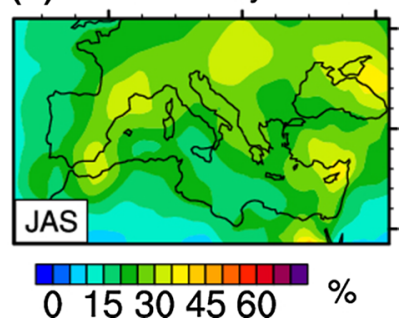

Fig. 8 RIV values (\%) for $\mathbf{a}, \mathbf{b}$ the full cyclones population; $\mathbf{c}, \mathbf{d}$ the cyclogenesis population; $\mathbf{e}, \mathbf{f}$ the cyclolysis population; and $\mathbf{g}, \mathbf{h}$ the intense cyclones population, in winter (left) and summer (right). The RIV is determined from the 10 members of ALADIN as explained in Sect. 2.3. Intense cyclones are defined as cyclones exceeding the threshold value of $170 \times 10^{-6} \mathrm{~s}^{-1}$ during at least one time-step

are more affected by the IV. On the other hand, a similar tercile classification of the full $\mathrm{V}$ distribution shows that the three groups are equivalent in terms of IV (not shown). For this reason, we decided to identify $\mathrm{V}$ sub-populations according to increasing $\mathrm{D}$ values. Then the $\mathrm{D}$ population is divided again in different groups, but now according to the deciles of the distribution. For each cyclone group corresponding to the each of the 10 deciles of $\mathrm{D}$, a subclassification in deciles for $\mathrm{V}$ is performed. For example, the cyclone population belonging to the decile $\mathrm{d} 1$ of $\mathrm{D}$ is split in turn into 10 deciles according to the values of $\mathrm{V}$. Figure 9 shows the RIV (a, b), IV (c, d) and TV (e, f) corresponding to the deciles of $\mathrm{V}$ for each of the deciles of D. In this case, the RIV, IV and TV have been averaged over the whole Mediterranean domain. In winter, the RIV maximum $(>25 \%)$ is found for largest values of $\mathrm{D}$ and $\mathrm{V}$,

indicating that the effects of IV are enhanced for long and fast travelling cyclone tracks (Fig. 9a). Higher values of RIV are also noticeable for lower D and V deciles ( $>20 \%)$, which suggest that static cyclones can be also an important source of IV (Fig. 9a, c). In summer, the RIV maxima correspond to long travelling cyclones (largest $\mathrm{D}$ values) moving at medium velocities, between the $\mathrm{d} 4\left(7 \mathrm{~m}^{*} \mathrm{~s}^{-1}\right)$ and $\mathrm{d} 7$ $\left(9.5 \mathrm{~m}^{*} \mathrm{~s}^{-1}\right)$ of the $\mathrm{V}$ distribution (Fig. $\left.9 \mathrm{~b}\right)$. As for winter, short and slow moving cyclone tracks are also related to large IV and TV values, resulting in a strong RIV (Fig. 9b, d, f).

\subsection{Temporal behaviour of the internal variability}

In this subsection we analyse the temporal evolution of the RIV for the PSL, T2 m, PR and DCT over the entire Mediterranean domain. RIV time-series (Fig. 10a, b) show several bursts during the simulation, which appear at the same time for all the variables. The RIV fluctuates in time, but it does not exhibit a temporal trend. It is useful to quantify the RIV on longer timescales, since for climate studies, variables are often computed at monthly and seasonal timescales. RIV time series are then recomputed from monthly and seasonal means for the different variables (not shown here). As expected, RIV values are considerably reduced (but are not negligible) as the timescale increases. For example, for PR and DCT, RIV rarely exceeds 20 and $50 \%$ respectively when it is computed from monthly means.

As in Lucas-Picher et al. (2008a), we have analysed the robustness of the IV estimates for different ensemble sizes. The RIV time-series are computed considering 2, 4, 6, 8, and 10 members, only for the precipitation. Figure 10c, d shows the RIV time-series for PR estimated from different ensemble sizes. In general for both seasons, ensembles of more than 6 members are necessary to obtain a robust estimation of RIV. This result is consistent with the study of Lucas-Picher et al. (2008a), who found that for the North American domain, a minimum of 6 members is adequate to obtain a robust inter-member spread.

\subsection{Internal variability and large-scale atmospheric circulation}

The anomalous atmospheric circulation associated to highest levels of internal variability of ALADIN is investigated in this section. This has been previously addressed for an ensemble of RCMs operating over the European domain from the EU-FP6 ENSEMBLES project, by using four North Atlantic weather regimes (Sanchez-Gomez et al. 2008); and over the South Africa domain by Crétat et al. (2011), through a weather type approach. For Europe, Sanchez-Gomez et al. (2008) found that Blocking 
Fig. 9 a, b RIV values (\%) averaged over the whole Mediterranean domain for the 10 deciles of the mean velocity distribution $(\mathrm{V})$ for each of the 10 deciles of the travelled distance distribution (D). The vertical axis indicates the deciles of $\mathrm{D}$. The horizontal axis refers to the 10 deciles of V. For example, the cyclones population belonging to the decile $\mathrm{d} 1$ of $\mathrm{D}$ is split in turn into 10 deciles according to the values of $\mathrm{V}$. The same configuration is shown for IV c, $\mathbf{d}$ and TV e, f respectively. Note that for IV and TV the color labels are different. Units in $\mathbf{c}, \mathbf{f}$ are tracks per season

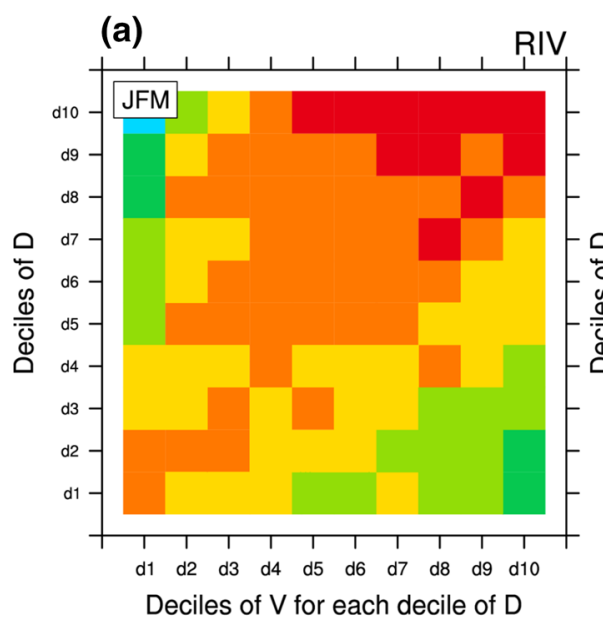

(c)

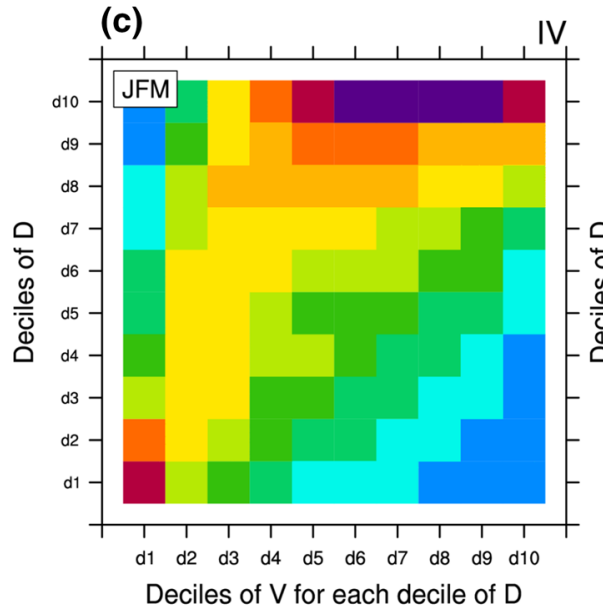

(e)

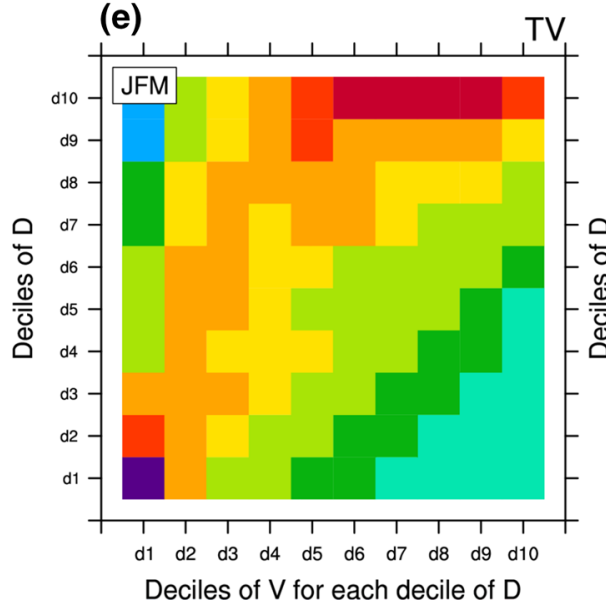

(b)

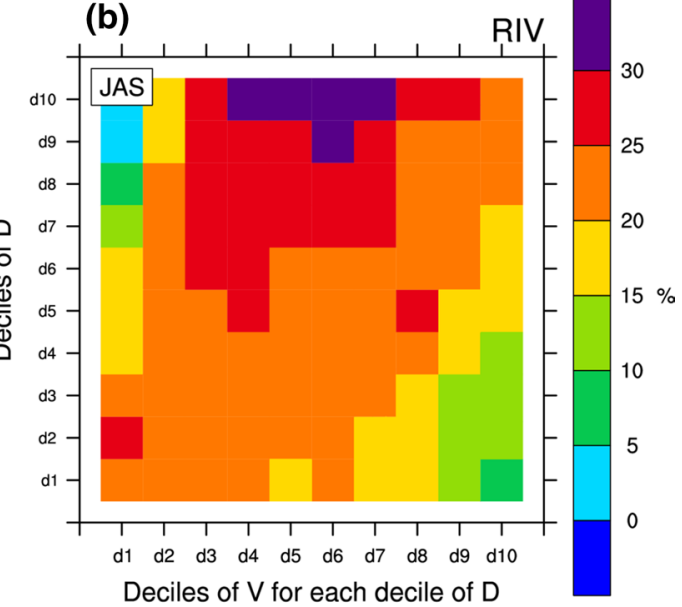

(d)

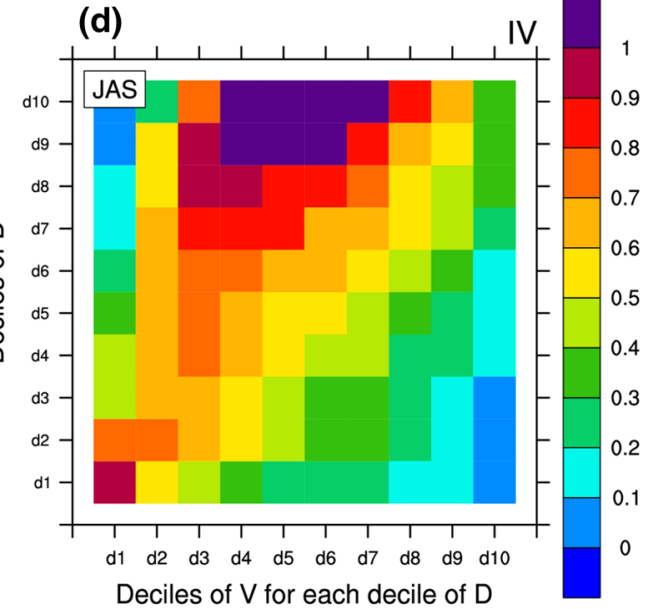

(f)

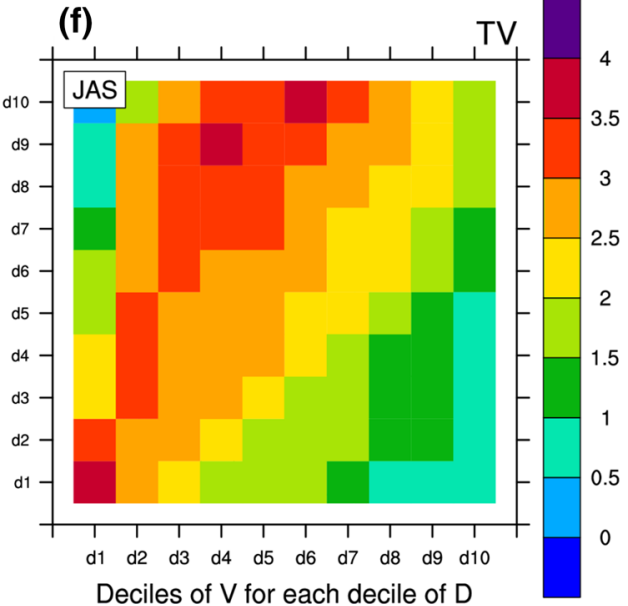

situations are associated to the largest values of inter-model spread for summer and winter.

In the present case, we analyse the atmospheric circulation related to highest RIV by conducting a composite approach, which differs from the weather typing methodologies mentioned above. This consists of selecting first those days where the RIV values exceed the $90 \%$ percentile of RIV of the precipitation time-series from Fig. 10a, b. This allows for the selection of $10 \%$ of the total number of days, which corresponds to approximately 300 days for each season. A composite field of PSL anomalies is then computed by averaging all the selected days. PSL anomalies have been standardized to take into account the seasonal cycle (i.e. stronger anomaly amplitude in winter). Figure 11a, b shows the composite patterns for JFM and JAS obtained from ERAI for a spatial domain covering most of the North Atlantic and Mediterranean basins. The choice of this larger domain for ERAI is aimed at providing 
(a)

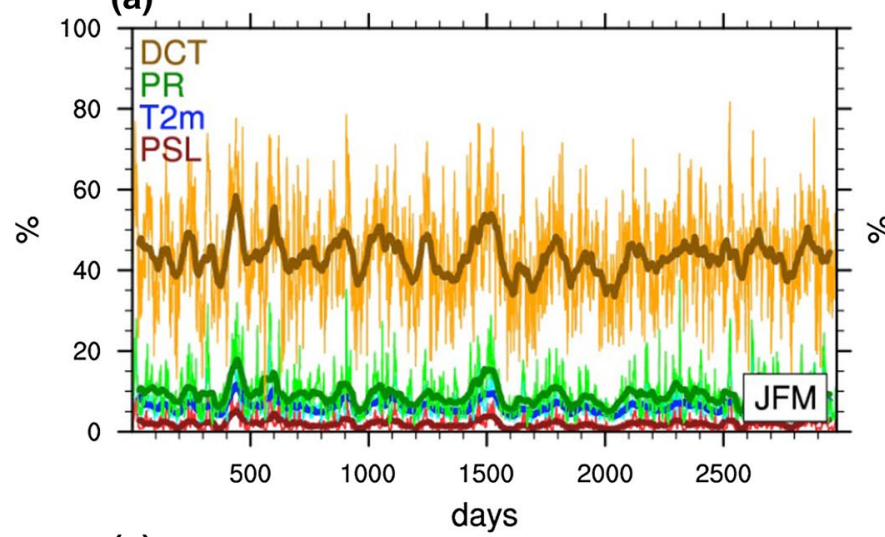

(c)

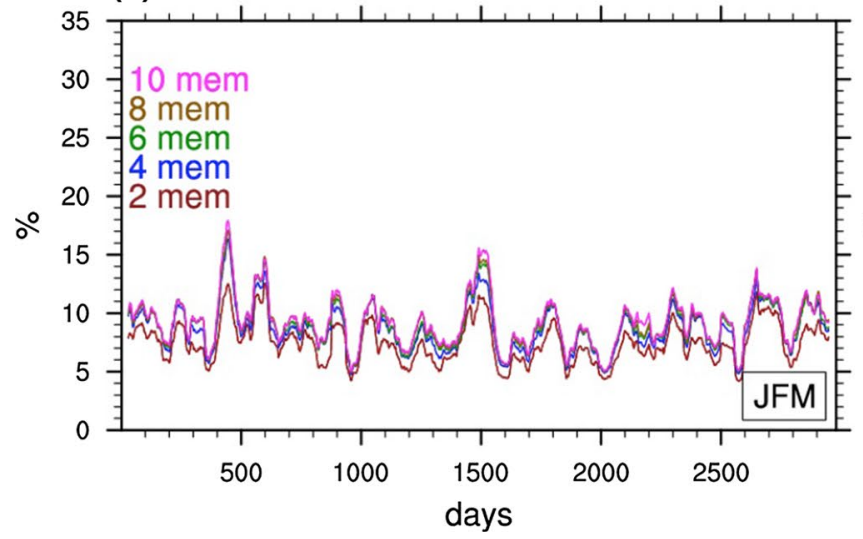

Fig. 10 RIV values of daily time series for JFM (a) and JAS (b) obtained by averaging the whole Mediterranean domain for several variables: sea level pressure (PSL), $2 \mathrm{~m}$ temperature (T2 m), precipitation (PR) and DCT. A 60 days running mean filter has been applied (thick lines) for readability. RIV values for daily time series for JFM (b)

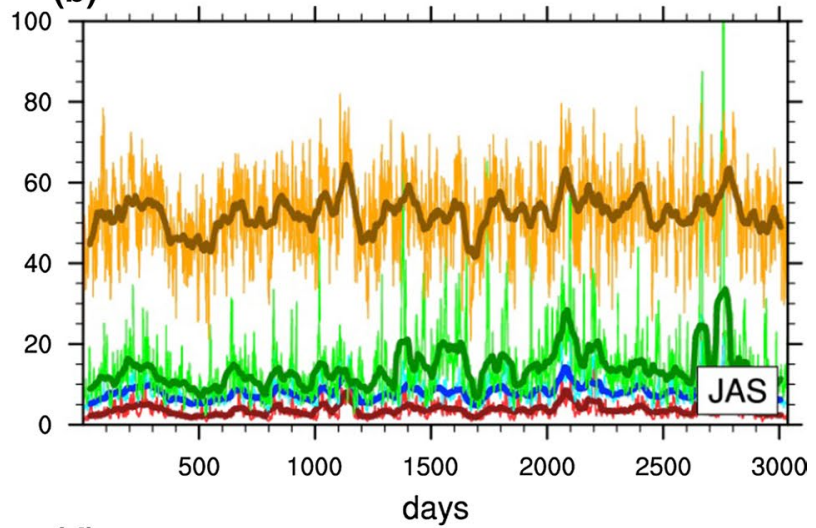

(d)

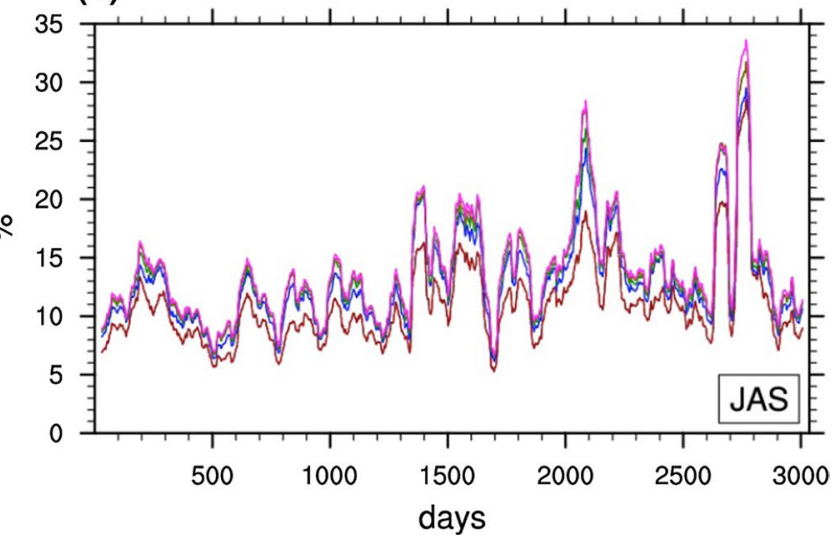

(c) and JAS (d) for the PR variable obtained by averaging the whole Mediterranean domain for several ensemble sizes: $2,4,6,8$ and 10 members. A 60 days running mean filter has been applied (thick lines) for readability purposes. Only filtered time-series are represented here
Fig. 11 a, b Sea level pressure standardized anomalies for ERAI reanalysis in JFM (a) and JAS (b) calculated by averaging all days exceeding the $90 \%$ quantile for the values of the RIV time-series of Fig. 11. Black dots areas indicate that anomalies are significant at the $95 \%$ confidence level. c, d Same but for the ALADIN ensemble mean. In this case the black dots indicate where the value of the ensemble mean is larger than the uncertainty generated by the inter-members spread according to a signalto-noise ratio estimated as described in the text (a)

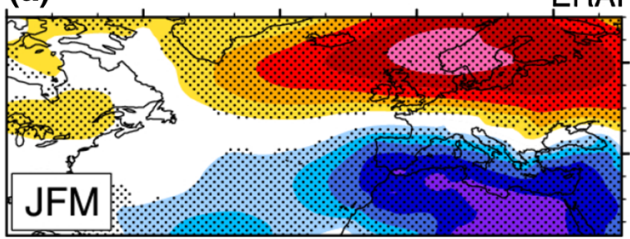

ERAI (b)

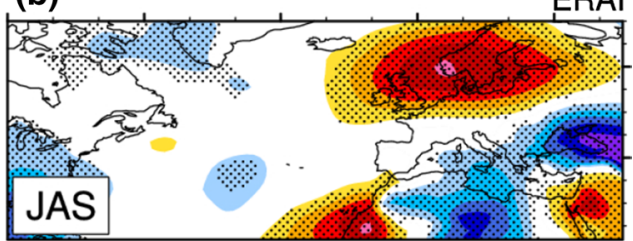

(c)

ALADIN (d)

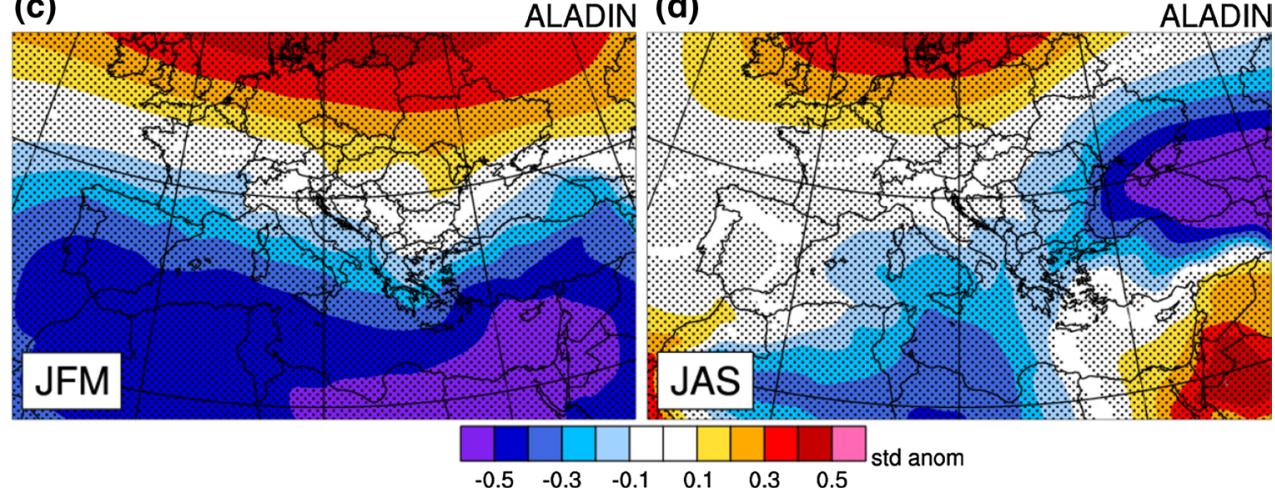


a broader view of the large-scale atmospheric conditions. Statistical significance has been addressed by a MonteCarlo non-parametric test, in which days randomly selected have been used to generate a large number (1000) of "synthetic" composites. In both seasons (Fig. 11a, b), the SLP structure presents positive anomalies over the northern boundary of the domain, centered over the Scandinavian Peninsula, which extends also eastwards covering all the northern Europe, and significant negative anomalies over the southern Mediterranean. This SLP spatial pattern is similar to the Scandinavian Blocking (Barston and Livezey 1987), which exhibits a more zonal and weaker westerly atmospheric flow, leading to a weakening of the ERAI forcing at the ALADIN boundaries. The Blocking pattern was also documented in Sanchez-Gomez et al. (2008) as being strongly related to large IV. Figure 11c, d shows the same composite patterns for the ensembles mean of ALADIN. A signal-to-noise ratio has been computed for each grid point as the ratio between the ensembles mean and the inter-member standard deviation, weighted to include the uncertainty due to the ensemble size (10 members) taking into account a Student law distribution (Hasselmann 1993, Zwiers and Zhang 2003). The patterns for ALADIN shows that all the members display the same PSL anomalies as for ERAI with a strong signal-to-noise ratio, indicating a strong agreement amongst the members to represent these large-scale pattern under largest IV conditions.

\section{Summary and conclusion}

The internal variability of the regional model ALADIN operating over the Med-CORDEX domain has been investigated from a 10-member ensemble. This ensemble, at $50 \mathrm{~km}$ horizontal resolution, is driven by ERAI surface and lateral boundary conditions for the period 1979-2012 and only the initial conditions are perturbed. The IV studies are rare in the CORDEX community and, to our knowledge; this is the first one on the widely-used Med-CORDEX domain. Moreover, for the first time, the study analyses the RCM IV effects on the Mediterranean cyclones.

The spatial distribution of the Relative Internal Variability (RIV) over the Mediterranean region for variables such as sea level pressure, $2 \mathrm{~m}$ temperature or precipitation presents high similarities to the studies based on the North America domain (Lucas-Picher et al. 2008a, among others cited in the introduction), and shows the largest RIV values located over the easternmost part of the domain (around Black Sea and Turkey). This indicates that RIV increases eastwards as the control exerted by the large-scale westerly flow at the western boundary weakens. A large seasonality associated to the RIV strength is reported, with RIV values stronger in summer than in winter. As shown by
Alexandru et al. (2007) and Cretat et al. (2011), the RIV largely depends on the location of the RCM domain, since the background large-scale atmospheric flow highly modulates the spatial structure and RIV strength. In the present case, the Mediterranean domain is largely controlled by the westerly North Atlantic flow at the western boundaries. Consequently, RIV presents strongest values over the eastern part of the Mediterranean basin. When the westerly flow weakens and shifts northwards in summer, the RCM is less controlled by the large-scale flow, and the ALADIN members exhibit stronger RIV values.

Temporal evolution of RIV shows several burst occurring over the analysed period. We show here that the largescale conditions associated with those days of RIV bursts occurrence are reminiscent of the Scandinavian Blocking. This pattern is characterized by a stronger anticyclone circulation centered over the north of the domain, which reduces the strength of the North Atlantic westerly flow. Similar results were found for the European domain in Sanchez-Gomez et al. (2008), by using the EU-FP6 ENSEMBLES multi-model database. They identified the Scandinavian Blocking as the atmospheric pattern excited in those periods in which the different RCMs, forced by the same LBCs, showed the largest discrepancies.

In the Mediterranean domain, our results show that with ALADIN model, an ensemble of 6 members seems sufficient to achieve a robust RIV estimate, as the inter-member spread does not change when more members are added to the ensemble. Others studies, as Crétat et al. (2011) or Nikiema and Laprise (2011a, b), found out that for RCM domains located at high latitudes, as the Arctic where the IV is very strong, more than 20 members are needed to avoid biases in the estimation of the inter-member spread.

Concerning the Mediterranean cyclones, the RIV for the Density of Cyclone Track (DCT) presents stronger values compared to other variables such as precipitation ( $\sim 50 \%$ for DCT versus $25 \%$ for precipitation). As for the other variables, the RIV is larger in summer than in winter, in particular over the Iberian Peninsula, northern Africa countries and eastern Mediterranean, which are regions of enhanced cyclogenesis during the warm season. The larger levels of RIV found for the DCT with respect to the others variables highlight the strong chaotic nature of the cyclone tracks, which can be easily deviated in one member with respect to another, in despite of sharing the same large scale atmospheric, SST and land surface forcing. Our results also show that Lagrangian-based methods used to detect and characterise extra-Mediterranean cyclones, as the tracking technique, are very sensitive to the chaotic variability, as highlighted by the high degree of randomness in the cyclone tracks. However, one interesting point emerges here: the RIV behaviour for the Mediterranean cyclones may be dependent in some degree of the tracking tool used 
to detect the cyclone tracks. It would be interesting to use other tracking method to identify the cyclone tracks in the ALADIN ensemble, in order to investigate whether the IV is modified.

To investigate more in detail the dependence of the RIV on the cyclone tracks, the RIV has been analysed according to the cyclone properties. We show here that, within the long travelling cyclones tracks population, those moving at faster mean velocities are associated to largest RIV. This is plausible, since even if the large-scale forcing is the same, longer tracks can be more easily deviated among the member by mesoscale disturbances related to convective processes, or local thermal gradients that change the baroclinicity. A secondary RIV maximum is also found for the stationary cyclones (those cyclones belonging to lowest deciles of the travelled distance distribution) in summer, suggesting that thermal lows are also an important source of RIV.

The studies dealing with the IV in regional modelling have provided so far a complete description of this phenomenon. Moreover some physical processes, acting as a source of IV are now better understood (Nikiema and Laprise 2011a, b). Nevertheless, there are still some remaining open questions that would deserve further investigation. For example: How the IV would be affected by increasing the regional model resolution? A higher horizontal resolution could intuitively generate more IV, but this needs to be properly demonstrated by numerical model experiments, by generating two ensembles at different model resolutions. Another unresolved issue is the role of the air-sea coupling on the IV; does a coupled regional model generate more IV compared to the stand-alone atmospheric component? Again, this question needs to be elucidated trough numerical approaches requiring high computational resources.

An interesting technique aimed at preventing the departures of an RCM from the driving conditions is the nudging methodology (Radu et al. 2008; Omrani et al. 2012). It has been shown that the use of nudging (or spectral nudging) clearly improves the model capacity to reproduce the forcing fields (Herrmann et al. 2011). Zahn et al. (2008) investigated the impact of the spectral nudging in the representation of polar lows in the Arctic. They showed that the spectrally nudged version of the regional model reproduces the observed polar lows in all the members of the ensemble, reducing significantly the inter-members spread. In a similar study, Feser and Barcikowska (2012) showed that the spectral nudging technique improves the representation of typhoons tracks in the Pacific ocean, reducing some of the biases with respect to the observed best track data.

Our results are encouraging to explore the usefulness of nudging techniques in regional modelling, in particular when the scope is the study of mesoscale processes such as the Mediterranean cyclones. Future work is needed to investigate the nudging effects on ALADIN over the Mediterranean domain, in particular on: (1) the ALADIN deficiencies in capturing the incoming North Atlantic cyclones at the western boundaries; and (2) the strong levels of IV in simulating the Mediterranean cyclones documented here. An analysis of IV on a spectrally nudged version of ALADIN will allow to better disentangling the role of the large scale forcing from the mesoscale processes, and would give further understanding of the large IV values in the cyclone tracks found here.

Our results also indicate that the internal model variability is a factor that should be considered in the design, analysis, and interpretation of RCM experiments.

Acknowledgements This work is a contribution to the HyMeX programme (HYdrological cycle in the Mediterranean EXperiment) through INSU-MISTRALS support and to the Med-CORDEX program (Coordinated Regional climate Downscaling EXperimentMediterranean region, www.medcordex.eu). This research has received funding from the French National Research Agency (ANR) project REMEMBER (contract ANR-12-SENV-001) and HyMeX program. The authors would like to give special thanks to the three anonymous reviewers for the "long" time spent in the review of the manuscript and for providing very constructive input.

Open Access This article is distributed under the terms of the Creative Commons Attribution 4.0 International License (http://creativecommons.org/licenses/by/4.0/), which permits unrestricted use, distribution, and reproduction in any medium, provided you give appropriate credit to the original author(s) and the source, provide a link to the Creative Commons license, and indicate if changes were made.

\section{References}

Alexandru A, de Elia R, Laprise R (2007) Internal variability in regional climate downscaling at the seasonal time scale. Mon Weather Rev 135:3221-3238. doi:10.1175/MWR3456.1

Ayrault F, Joly A (2000) Une nouvelle typologie des uwpresssions météorologiques: classification des phases de maturation. Compte-Rendus à l'Académie des Sciences (CRAS) Sciences de la Terre et des planètes 330:167-172

Barnston AG, Livezey RE (1987) Classification, seasonality and persistence of low-frequency atmospheric circulation patterns. Mon Weather Rev 115:1083-1126

Campins J, Genoves A, Picornelland MA, Jansa A (2011) Climatology of Mediterranean cyclones using the ERA-40 dataset. Int $\mathrm{J}$ Climatol 31:1596-1614

Caya D, Biner S (2004) Internal variability of RCM simulations over an annual cycle. Clim Dyn 22:33-46

Christensen OB, Gaertner MA, Prego JA, Polcher J (2001) Internal variability of regional climate models. Clim Dyn 17:875-887. doi:10.1007/s003820100154

Colin J, Déqué M, Radu R, Somot S (2010) Sensitivity study of heavy precipitations in limited area model climate simulation: influence of the size of the domain and the use of the spectral nudging technique. Tellus A 62(5):591-604. doi:10.1111/j.1600-0870.2010.00467.x

Crétat J, Macron C, Pohl B, Richard Y (2011) Quantifying internal variability in a regional climate model: a case study for Southern Africa. Clim Dyn 37:1335-1356 
Davies HC (1976) A lateral boundary formulation for multi-level prediction models. Q J R Meteorol Soc 102:405-418

de Elia R, Caya D, Frigon A, Coté H, Giguère M, Paquin D, Biner S, Plummer D (2007) Evaluation of uncertainties in the CRCM simulated North American climate: nesting-related issues. Clim Dyn 30:113-132. doi:10.1007/s00382-007-0288-z

Dee DP et al (2011) The ERA-interim reanalysis, configuration and performance of the data assimilation system. Q J R Meteorol Soc 137:553-597

Déqué M (2010) Regional climate simulation with a mosaic of RCMs. Meteorol Z 19(3):259-266

Déqué M, Somot S (2008) Extreme precipitation and high resolution with Aladin. Idojaras Q J Hung Meteorol Serv 112(3-4):179-190

Feser F, Barcikowska M (2012) The influence of spectral nudging on typhoon formation in regional climate models. Environ Res Lett 7:014024. doi:10.1088/1748-9326/7/1/

Flaounas E, Drobinski P, Bastin S (2013) Dynamical downscaling of IPSL-CM5 CMIP5 historical simulations over the Mediterranean: benefits on the representation of regional surface winds and cyclogenesis. Clim Dyn 40:2497-2513

Flaounas E, Raveh-Rubin S, Wernli H, Drobinski P, Bastin S (2014) The dynamical structure of intense Mediterranean cyclones. Clim Dyn 44:2411-2427. doi:10.1007/s00382-014-2330-21-17

Flaounas E, Gaertner M, Kelemen F, Lionello P, Sanchez-Gomez E, Wernli H, Naveed A, Calmanti S, Conte D, Podrascanin Z, Reale M, Romera R, Somot S (2016) Assessment of an ensemble of ocean-atmosphere coupled and uncoupled regional climate models to reproduce the climatology of Mediterranean cyclones, Clim Dyn, in revision

Gaertner MA, Fernández C, Castro M (1993) A two-dimensional simulation of the Iberian summer thermal low. Mon Weather Rev 121:2740-2756

Gaertner MA, Jacob D, Gil V, Domínguez M, Padorno E, Sánchez E, Castro M (2007) Tropical cyclones over the Mediterranean Sea in climate change simulations. Geophys Res Lett 34:L14711. doi :10.1029/2007GL029977

Giorgi F, Bi X (2000) A study of internal variability of a regional climate model. J Geophys Res 105:29503-29521

Giorgi F, Jones C, Asrar GR (2009) Addressing climate information needs at the regional level: the CORDEX framework. World Meteorol Org (WMO) Bull 58:175

Hasselmann K (1993) Optimal fingerprints for the detection of timedependent climate change. J Clim 6:1957-1971

Herrmann M, Somot S, Calmanti S, Dubois C, Sevault F (2011) Representation of daily wind speed spatial and temporal variability and intense wind events over the Mediterranean Sea using dynamical downscaling: impact of the regional climate model configuration. Nat Hazards Earth Syst Sci 11:1983-2001. doi:10.5194/nhess-11-1983-2011

Jacob D, Petersen J, Eggert B, Alias A, Christensen OB, Bouwer L, Braun A, Colette A, Déqué M, Georgievski G, Georgopoulou E, Gobiet A, Menut L, Nikulin G, Haensler A, Hempelmann N, Jones C, Keuler K, Kovats S, Kröner N, Kotlarski S, Kriegsmann A, Martin E, Meijgaard E, Moseley C, Pfeifer S, Preuschmann S, Radermacher C, Radtke K, Rechid D, Rounsevell M, Samuelsson P, Somot S, Soussana J-F, Teichmann C, Valentini R, Vautard R, Weber B, Yiou P (2013) EURO-CORDEX: new high-resolution climate change projections for European impact research regional environmental change. Springer, Berlin Heidelberg, pp $1-16$

Jansà A, Genovés A, Picornell MA, Campins J, Riosalido R, Carretero O (2001) Western Mediterranean cyclones and heavy rain, Part 2: statistical approach. Meteor Appl 8:43-56

Kgatuke MM, Landman WA, Beraki A, Mbedzi MP (2008) The internal variability of the RegMC3 over South Africa. Int J Climatol 28:505-520
Laprise R, de Elia R, Caya D, Biner S, Lucas-Picher P, Diaconescu E, Leduc M, Alexandru A, Separovic L (2008) Challenging some tenets of regional climate modelling. J Comp Phys Special issue on Predicting weather, climate and extreme events, 277, 3641-3666

Lionello P, Bhend J, Buzzi A, Della-Marta PM, Krichak SO, Jansa A, Maheras P, Sanna A, Trigo IF, Trigo R (2006) Cyclones in the mediterranean region: Climatology and effects on the environment. In: Lionello P, Malanotte-Rizzoli P, Boscolo R (eds) Mediterranean climate variability, developments in earth and environmental sciences, 4. Elsevier, Amsterdam, pp 325-372

Lionello P, Boldrin U, Giorgi F (2008) Future changes in cyclone climatology over Europe as inferred from a regional climate simulation. Clim Dyn 30:657-671. doi:10.1007/s00382-007-0315-0

Lucas-Picher P, Caya D, de Elia R, Laprise R (2008a) Investigation of regional climate models' internal variability with a ten-member ensemble of ten-year simulations over a large domain. Clim Dyn. doi:10.1007/s00382-008-0384-8

Lucas-Picher P, Caya D, Biner S, Laprise R (2008b) Quantification of the lateral boundary forcing of a regional climate model using an ageing tracer. Mon Weather Rev. doi:10.1175/2008MWR2448.1

Lucas-Picher P, Somot S, Déqué M, Decharme B, Alias A (2013) Evaluation of the regional climate model ALADIN to simulate the climate over North America in the CORDEX framework. Clim Dyn 41:1117-1137. doi:10.1007/s00382-012-1613-8

Maheras P, Flocas HA, Patrikas I, Anagnostopoulou C (2001) A 40 year objective climatology of surface cyclones in the Mediterranean region: spatial and temporal distribution. Int $\mathbf{J}$ Climatol 21:109-130

Neu U, Akperov MG, Bellenbaum N, Benestad R, Blender R, Caballero R, Cocozza A, Dacre HF, Feng Y, Fraedrich K, Grieger J, Gulev S, Hanley J, Hewson T, Inatsu M, Keay K, Kew SF, Kindem I, Leckebusch GC, Liberato MLR, Lionello P, Mokhov II, Pinto JG, Raible CC, Reale M, Rudeva I, Schuster M, Simmonds I, Sinclair M, Sprenger M, Tilinina ND, Trigo IF, Ulbrich S, Ulbrich U, Wang XL, Wernli H (2012) IMILAST—a community effort to intercompare extratropical cyclone detection and tracking algorithms: assessing method-related uncertainties. Bull Am Meteorol Soc 94:529-547. doi:10.1175/BAMS-D-11-00154.1

Nikiema O, Laprise R (2011a) Diagnostic budget study of the internal variability in ensemble simulations of the Canadian RCM. Clim Dyn 36:2313-2337. doi:10.1007/s00382-010-0834-y

Nikiema O, Laprise R (2011b) Budget study of the internal variability in ensemble simulations of the Canadian RCM at the seasonal scale. J Geophys Res Atmos. doi:10.1029/2011JD015841

Nikulin G, Jones C, Giorgi F, Asrar G, Büchner M, Cerezo-Mota R, Sushama L (2012) Precipitation climatology in an ensemble of CORDEX-Africa regional climate simulations. J Clim 25:6057-6078

Nissen KM, Leckebusch GC, Pinto JG, Renggli D, Ulbrich S, Ulbrich U (2010) Cyclones causing wind storms in the Mediterranean: characteristics, trends and links to large-scale patterns. Nat Hazards Earth Syst Sci 10:1379-1391. doi:10.5194/ nhess-10-1379-2010

Omrani H, Drobinski P, Dubos T (2012) Spectral nudging in regional climate modelling: how strongly should we nudge? Q J R Meteor Soc 138:1808-1813. doi:10.1002/qj.1894

Radu R, Déqué M, Somot S (2008) Spectral nudging in a spectral regional climate model. Tellus A 5:885-897. doi:10.1111/j.1600-0870.2008.00343.x

Raveh-Rubin S, Wernli H (2015) Large-scale wind and precipitation extremes in the Mediterranean - a climatological analysis for 1979 2012. Q J R Meteorol Soc 141:2404-2417. doi:10.1002/qj.2531

Rinke A, Dethloff K (2000) On the sensitivity of a regional Arctic climate model to initial and boundary conditions. Clim Res 14:101-113 
Rinke A, Marbaix P, Dethloff K (2004) Internal variability in Arctic regional climate simulations: case study for the Sheba year. Clim Res 27:197-209

Ruti P, Somot S, Giorgi F, Dubois C, Flaounas E, Obermann A, Dell'Aquila A, Pisacane G, Harzallah A, Lombardi E, Ahrens B, Akhtar N, Alias A, Arsouze T, Aznar R, Bastin S, Bartholy J, Beranger K, Beuvier J, Bouffies-Cloche S, Brauch J, Cabos W, Calmanti S, Calvet JC, Carillo A, Conte D, Coppola E, Djurdjevic V, Drobinski P, Elizalde A, Gaertner M, Galan P, Gallardo C, Gualdi S, Goncalves M, Jorba O, Jorda G, Lheveder B, Lebeaupin-Brossier C, Li L, Liguori G, Lionello P, Macias-Moy D, Onol B, Rajkovic B, Ramage K, Sevault F, Sannino G, Struglia MV, Sanna A, Torma C, Vervatis V (2015) MED-CORDEX initiative for Mediterranean climate studies. Bull Amer Meteor Soc. doi:10.1175/BAMS-D-14-00176.1

Sanchez-Gomez E, Somot S, Déqué M (2008) Ability of an ensemble of regional climate models to reproduce weather regimes over Europe-Atlantic during the period 1961-2000. Clim Dyn 35:L15706. doi:10.1007/s00382-008-0502-7

Sanchez-Gomez E, Somot S, Josey SA, Dubois C, Elguindi N, Déqué M (2011) Evaluation of Mediterranean Sea water and heat budgets simulated by an ensemble de high resolution regional climate models. Clim Dyn 37:2067-2086. doi:10.1007/s00382-011-1012-6

Separovic L, de Elía R, Laprise R (2008) Reproducible and irreproducible components in ensemble simulations with a regional climate model. Mon Weather Rev 136:4942-4961

Tegen I, Hollrig P, Chin M, Fung I, Jacob D, Penner J (1997) Contribution of different aerosol species to the global aerosol extinction optical thickness: estimates from model results. J Geophys Res 102:23895-23915
Tramblay Y, Ruelland D, Somot S, Bouaicha R, Servat E (2013) High-resolution Med-CORDEX regional climate model simulations for hydrological impact studies: a first evaluation of the ALADIN-Climate model in Morocco. Hydrol Earth Syst Sci 17:3721-3739. doi:10.5194/hess-17-3721-2013

Trigo IF, Davies TD, Bigg GR (1999) Objective climatology of cyclones in the Mediterranean region. J Clim 12:1685-1696. doi:10.1175/1520-0442

Trigo IF, Davies TD, Bigg GR (2000) Decline in Mediterranean rainfall caused by weakening of Mediterranean cyclones. Geophys Res Lett 27:2913-2916

Trigo IF, Bigg GR, Davies TD (2002) Climatology of cyclogenesis mechanisms in the Mediterranean. Mon Weather Rev 130:549-569

Vannitsem S, Chomé F (2005) One-way nested regional climate simulations and domain size. J Clim 18:229-233

Vanvyve E, Hall N, Messager C, Leroux S, Van Ypersele JP (2008) Internal variability in a regional climate model over West Africa. Clim Dyn 30:191-202

Walsh K, Giorgi F, Coppola E (2014) Mediterranean warm-core cyclones in a warmer world. Clim Dyn 42:1053-1066

Zahn M, von Storch H, Bakan S (2008) Climate mode simulation of North Atlantic polar lows in a limited area model. Tellus A 60:620-631. doi:10.1111/j.1600-0870.2008.00330.x

Zwiers F, Zhang X (2003) Toward regional scale climate detection. J Clim 16(5):793-797 